\title{
A New Hybrid BFOA-PSO Optimization Technique for Decoupling and Robust Control of Two-Coupled Distillation Column Process
}

\author{
Noha Abdelkarim, ${ }^{1}$ Amr E. Mohamed, ${ }^{1}$ Ahmed M. El-Garhy, ${ }^{1}$ and Hassen T. Dorrah ${ }^{2}$ \\ ${ }^{1}$ Department of Electronics, Communications and Computers, Faculty of Engineering, Helwan University, \\ 1 Sherif Street, Helwan, Cairo 11792, Egypt \\ ${ }^{2}$ Department of Electrical Engineering, Faculty of Engineering, Cairo University, University Street, Giza 12316, Egypt
}

Correspondence should be addressed to Noha Abdelkarim; noha.abdelkarim.ac@gmail.com

Received 22 April 2016; Revised 31 July 2016; Accepted 9 August 2016

Academic Editor: J. Alfredo Hernández-Pérez

Copyright ( $(2016$ Noha Abdelkarim et al. This is an open access article distributed under the Creative Commons Attribution License, which permits unrestricted use, distribution, and reproduction in any medium, provided the original work is properly cited.

\begin{abstract}
The two-coupled distillation column process is a physically complicated system in many aspects. Specifically, the nested interrelationship between system inputs and outputs constitutes one of the significant challenges in system control design. Mostly, such a process is to be decoupled into several input/output pairings (loops), so that a single controller can be assigned for each loop. In the frame of this research, the Brain Emotional Learning Based Intelligent Controller (BELBIC) forms the control structure for each decoupled loop. The paper's main objective is to develop a parameterization technique for decoupling and control schemes, which ensures robust control behavior. In this regard, the novel optimization technique Bacterial Swarm Optimization (BSO) is utilized for the minimization of summation of the integral time-weighted squared errors (ITSEs) for all control loops. This optimization technique constitutes a hybrid between two techniques, which are the Particle Swarm and Bacterial Foraging algorithms. According to the simulation results, this hybridized technique ensures low mathematical burdens and high decoupling and control accuracy. Moreover, the behavior analysis of the proposed BELBIC shows a remarkable improvement in the time domain behavior and robustness over the conventional PID controller.
\end{abstract}

\section{Introduction}

Controller design for multi-input multiple-output (MIMO) systems is of significant importance, as they constitute the majority of physical systems. However, the design of such controllers is confronted with the challenge to overcome the influence of the nested interrelationship between system inputs and outputs. Based on the level of interrelationship between system inputs and outputs, the control structure is to be selected. The systems, which are characterized with moderate interaction between control loops, can be controlled with the decentralized control structure so that a single controller is assigned for each control loop [1-5]. On the other hand, a centralized controller has to be designed for systems with higher level of interrelationship between control loops [6-9], so that a central matrix of controllers is allocated for the whole MIMO system. In spite of this, the centralized controllers are not widely utilized due to their high complexity. Alternatively, the issue of high interrelationship can be alleviated by decoupling the MIMO system into several relatively independent single-input single-output (SISO) control loops [10-15]. Accordingly, the multivariable process can be controlled based on independent loop structure. In this paper, the decoupled control structure is utilized for controlling the presented MIMO system. For the decoupler to be designed, the adequate input-output pairings are primarily determined through the evaluation of the system relative gains [16-19]. Accordingly, the decoupling network has to be designed, so that the interaction between control loops is minimized $[20,21]$. For control purposes, conventional control schemes as PID can be utilized [22-24]. It is to mention that the nonlinearity and the model imprecision that characterize the majority of physical systems reduce the robustness and accuracy of such controllers.

Control design approaches based on intelligent algorithms as fuzzy logic, neural network, and genetic algorithms 
are of increasing spread due to their proven ability to overcome system model uncertainty [25-27]. The computational model of emotional learning in mammalian brain, which is introduced in $[28,29]$, inspired a new learning algorithm. Afterwards, this learning technique is deployed in the system control design presenting the novel Brain Emotional Learning Based Intelligent Controller (BELBIC) [30]. Thus, the Brain Emotional Learning Based Intelligent Controller (BELBIC) has shown robustness in the control of the nonlinear and uncertain systems such as Van Der Pol oscillator, Duffing forced oscillator and automatic self-balancing scale [31], washing machine [32], microheat exchanger [33], switched reluctance motor [34], unmanned aerial vehicle [35], path tracking of a vehicle [36], two-coupled distillation column process [37], multiple-area power systems [38], and continuous stirred tank reactor $[39,40]$.

The parameterization of the decoupling compensation network and the BELBIC are still open research topics. Currently, the detailed analytical methods used in purpose of the parameterization of the decoupling compensation network cost excessive mathematical burdens. Regarding the parameterization of BELBIC, the trial and error is widely used for controller parameters estimation. Thus, the utilization of various optimization techniques based on artificial intelligence introduces an efficient alternative in both cases [11, 37].

The utilization of the biologically inspired algorithms as Ant Colony Optimization (ACO) [41], Genetic Algorithm (GA) [42], and Particle Swarm Optimization (PSO) [43, 44] in optimization problems constitutes currently a promising solution. Recently, the new evolutionary computation technique depending on the behavior of foraging of E. coli bacteria, which is named as Bacterial Foraging Optimization Algorithm (BFOA), is proposed by [45]. This technique has been successfully deployed in many applications as power systems [46-49], stock market prediction [50, 51], and design of PI/PID controllers $[52,53]$. The key drawback of the BFOA is the delay in reaching the global solution because it is based on random searching directions. For this delay to be overcome, the BFOA is integrated with the Particle Swarm Optimization (PSO) technique, introducing the Bacterial Swarm Optimization (BSO) algorithm [54]. One of the major characteristics of PSO technique, which is inherited to the $\mathrm{BSO}$ algorithm, is the idea of velocity updating. Accordingly, the process of searching for the global solution in the BSO technique depends on the individual and global best positions concurrently. As discussed in [55-58], The Bacterial Swarm Optimization (BSO) algorithm grants better performance in determining the optimum solution compared with PSO and BFOA algorithms.

This research paper aims to investigate the feasibility of applying the Bacterial Swarm Optimization (BSO) algorithm in the field of MIMO control system. As an example for MIMO system the two-coupled distillation column is to be studied. Primarily, the mathematical model of the system is decoupled into several independent loops. The parameters of the decoupling compensation network are determined based on the summation minimization of the integral timeweighted squared outputs (ITSOs) of unpaired outputs regarding a particular input. In this regard, the BSO technique is utilized. On the other hand, an optimal BELBIC is designed for each decoupled control loop through the summation minimization of the integral time-weighted squared errors (ITSEs) of all loops using BSO as well. For the comparison purpose the PID controller is also implemented for the same application, so that the strength of each of considered control structures can be studied.

\section{Two-Coupled Distillation Column Process}

As formerly stated, the two-coupled distillation column is handled in this paper as an example of MIMO system. In this section, the physical system is discussed. Primarily, the function of the system and its components are presented. Afterwards, the system mathematical modeling and decoupling are handled.

2.1. System Description. Distillation units are mainly utilized for the separation of fluid mixture components. The distillation column major components can be listed as follows:

(i) A vertical shell in which the separation of fluid substances is accomplished

(ii) A cascade of trays for improving component separation

(iii) A reboiler for maintaining the required heat energy for the distillation process

(iv) A condenser for liquefying the vapor leaving the column

(v) A reflux drum in which portion of the condensed liquid is recycled back to the vertical shell.

The physical process considered in this research comprises two-coupled distillation columns as shown in Figure 1. Thereby, ternary petrochemical mixtures can be separated. While the main glass column is composed of 40 bubble cap trays excluding those of the boiler and condenser, the side glass column contains 10 bubble cap trays. At the 22nd stage, the system intake port is located, at which the fluid mixture is to be fed. The three separated fluid components are to be extracted from the process, so that the heaviest and the lightest components can be provided from the bottom and the top of the main column, respectively, and the intermediate component is derived from the top of the side column.

\subsection{Mathematical Modeling of the Two-Coupled Distillation} Column. Primarily, the manipulated variables are to be determined. Thus, the selected manipulated variables are the heat input to the reboiler $(\mathrm{QE})$, the vapor flow rate in the vapor transfer line $(\mathrm{SAB})$, the reflux ratio in the main column (RL1), and the reflux ratio in the second column (RL2) [59]. Regarding the system technical constraints, the input heat energy rate $\mathrm{QE}$ and the vapor flow rate $\mathrm{SAB}$ have to not exceed the values $8.2 \mathrm{KW}$ and $3.95 \mathrm{~m}^{3} / \mathrm{h}$, respectively, in order to avoid flooding of the smaller side column [59]. Secondly, the controlled values are selected to be the fluid temperature at 


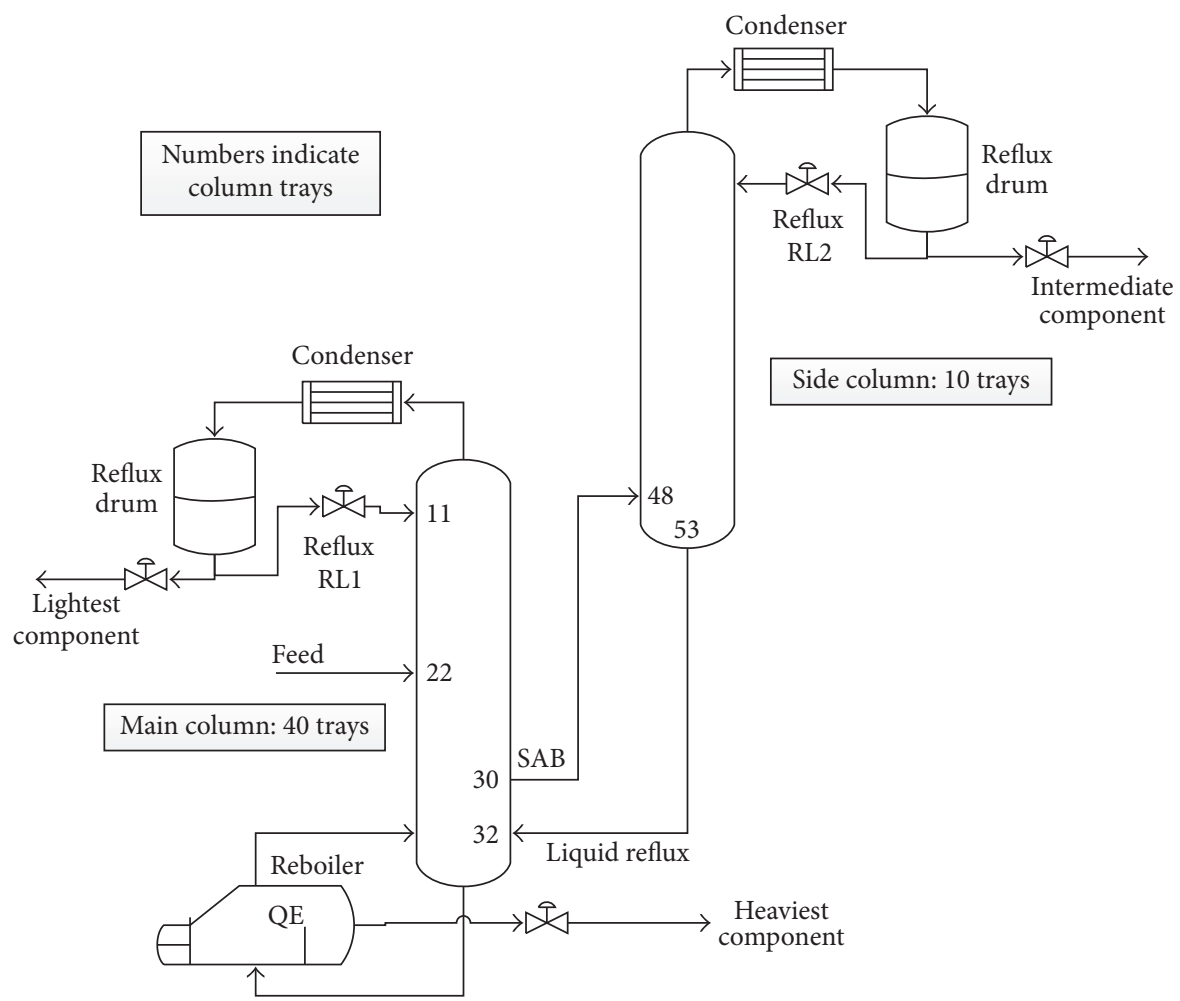

FIGURE 1: The two-coupled distillation columns process.

four different stages. The selection of these stages is based on the following requirements:

(i) The temperatures should be sensitive to the major disturbances as changes in feed rate and feed concentrations.

(ii) The temperatures should exhibit a fairly linear behavior.

$$
G(s)=\left[\begin{array}{cc}
\frac{2.6}{1.69 s+1} & \frac{-6.098}{3.5 s+1} \\
\frac{7.32(1.05 s+1)}{(10.4 s+1)(0.14 s+1)} & \frac{-1.45}{0.4 s+1} \\
\frac{4.6(0.53 s+1)}{(2.78 s+1)(0.09 s+1)} & \frac{-2.37(0.23 s+1)}{(2 s+1)(0.3 s+1)} \\
\frac{2.11}{0.92 s+1} & \frac{-2.11(0.06 s+1)}{(2.38 s+1)(0.05 s+1)}
\end{array}\right.
$$

(iii) They should be a good indication of product quality.

Accordingly, the temperature at the 11th, 30th, 34th, and 48th trays are chosen to form the controlled variables [59]. The mathematical model of realistic two-coupled distillation column, mentioned in [59], is to be used in this research. The transfer function matrix of the considered MIMO system is stated in (1).

$$
\left.\begin{array}{cc}
\frac{-4.99(0.2 s+1)}{(4.5 s+1)(0.06 s+1)} & \frac{0.071}{3.5 s+1} \\
\frac{-1.57(0.23 s+1)}{(1.34 s+1)(0.2 s+1)} & \frac{-0.14}{1.92 s+1} \\
\frac{-2.7}{1.75 s+1} & \frac{-0.36(0.02 s+1)}{(2.47 s+1)(0.04 s+1)} \\
\frac{-1.75}{2.16 s+1} & \frac{-0.3(1.89 s+1)}{(4.35 s+1)(0.16 s+1)}
\end{array}\right] \text {. }
$$

As shown in the transfer function matrix, the physical system is characterized by the high interrelationship between all system inputs and outputs. As discussed in the introduction, the control structure adopted in this paper is based on the mathematical model decoupling, so that each output is independently controlled by a single input, forming four independent SISO control loops.

Primarily, the noninteracting design is preceded by a relative gain analysis to determine the most suitable inputoutput pairings. In this regard, the relative gain array (RGA) method is used. Afterwards, a decoupling compensation network is designed for the reduction of residual interactions [11].

2.2.1. The Relative Gain Array. The RGA matrix for $N \times N$ system represented in (2) is used for the valuation of the input influences on each system output [16-19], so that output " $i$ " is to be paired with input " $j$ " for which $\gamma_{i j}$ is a positive value and as close to unity as possible. 


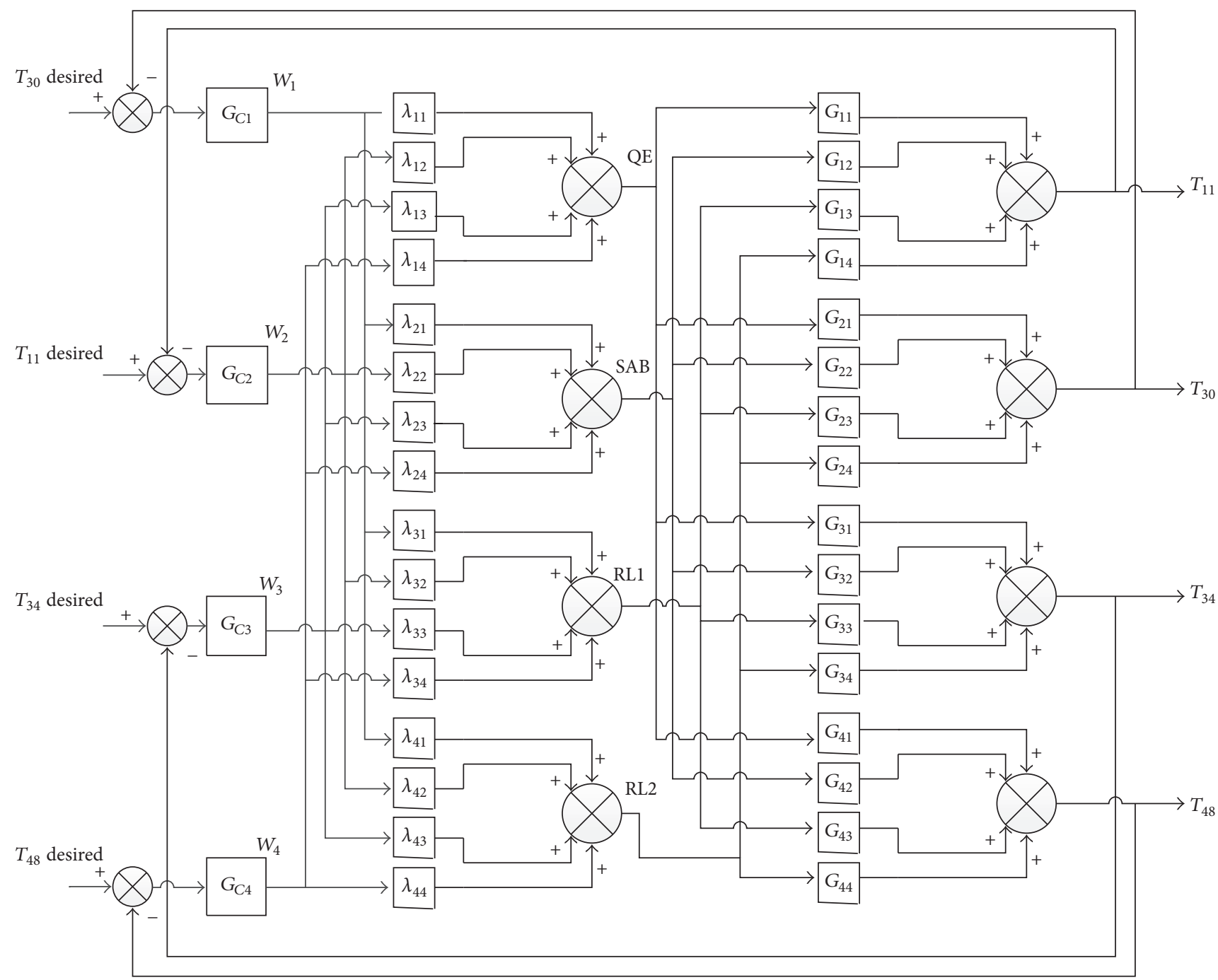

FIgURE 2: The decoupled MIMO system including controllers.

$$
\begin{aligned}
\operatorname{RGA}_{N \times N} & =[G(s=0)] \cdot *[G(s=0)]^{-T} \\
& =\left[\begin{array}{cccc}
\gamma_{11} & \gamma_{12} & \cdots & \gamma_{1 N} \\
\gamma_{21} & \gamma_{22} & \cdots & \gamma_{2 N} \\
\vdots & \vdots & & \vdots \\
\gamma_{N 1} & \gamma_{N 2} & \cdots & \gamma_{N N}
\end{array}\right]
\end{aligned}
$$

where $G(s)$ is the transfer function matrix of the MIMO process and “**" operator implies element by element multiplication.

2.2.2. Decoupling Compensation Network Design Procedure. The steady state decoupling compensation matrix illustrated in (3) is to be integrated into the given MIMO system in the way demonstrated in (4), so that interrelationships between each input and unpaired outputs is minimized [20, 21]. In this paper, the simplest form of the decoupling compensation matrix introduced in the previous study [11], which has unity diagonal elements, is replaced with the general form presented in (3). This modification introduces a remarkable improvement in the system response as discussed in Section 5. Figure 2 illustrates the decoupling compensation network scheme integrated with the required controllers.

$$
\begin{aligned}
\Lambda_{s s} & =\left[\begin{array}{cccccc}
\lambda_{11} & \lambda_{12} & \lambda_{13} & \cdots & \lambda_{1 N-1} & \lambda_{1 N} \\
\lambda_{21} & \lambda_{22} & \lambda_{23} & \cdots & \lambda_{2 N-1} & \lambda_{2 N} \\
\vdots & \vdots & \vdots & & \vdots & \vdots \\
\lambda_{N 1} & \lambda_{N 2} & \lambda_{N 3} & \cdots & \lambda_{N N-1} & \lambda_{N N}
\end{array}\right], \\
{[Y(s)] } & =[G(s)]\left[\Lambda_{s s}\right][W(s)],
\end{aligned}
$$

where $[Y(s)]$ is the output vector, $[W(s)]$ is the input vector, $[G(s)]$ is the transfer function matrix of the MIMO process, and $\left[\Lambda_{\mathrm{ss}}\right]$ is the steady state decoupling compensation matrix of MIMO process.

2.2.3. Fitness Function Design. As discussed in the former two sections, the determination of the adequate system input/ 
output pairing as well as the elements' values of the decoupling compensation matrix define the effectiveness of interrelationship minimization between system inputs and outputs. The selection of the proper input/output pairing is already tackled by the relative gain array concept. For the elements' values of the decoupling compensation matrix to be estimated using optimization techniques, the fitness functions have to be designed that minimize the interrelationship between system inputs and their unpaired outputs.

The four commonly used performance criteria for fitness function design are the integral absolute error (IAE), integral squared error (ISE), integral time-weighted squared error (ITSE), and Integral time-weighted absolute error (ITAE). It's to mention that in the context of decoupling system design, the performance criteria are concerned with the minimization of the system outputs towards the unpaired inputs rather than control system error. Accordingly, the corresponding criteria are integral absolute output (IAO), integral squared output (ISO), integral time-weighted squared output (ITSO), and Integral time-weighted absolute output (ITAO). Although the criteria ISO and IAO grant less overshoot in the system dynamics, none of these criteria is adopted in this research due to the long settling time [56]. This drawback could be overcome by utilizing the ITAO. However, this criterion is not used in this research for the difficulty of its analytical tracking [60]. Thus, the ITSO performance criterion is employed in this work for ensuring the minimization of settling time without being confronted with unnecessary analytical complications.

In the former research [11], the decoupling compensation matrix elements are estimated by applying the PSO technique, so that the integral squared outputs (ISOs) of unpaired outputs with respect to a specific input are minimized. On the other hand, the proposed technique in this paper is based on the minimization of the integral time-weighted squared outputs (ITSOs) by utilizing the BSO technique.

The integral time-weighted squared outputs (ITSOs) for each input are calculated such that

$$
\begin{aligned}
& \text { if } W_{1}(s)=1 / s \text { and } W_{2}, W_{3}, \ldots, W_{N} \text { are zeroes, then } \\
& \begin{aligned}
\text { ITSO }_{11}= & \int_{0}^{\infty} t\left\{Y_{1}\right\}^{2} \cdot d t \\
\text { ITSO }_{21} & =\int_{0}^{\infty} t\left\{Y_{2}\right\}^{2} \cdot d t \\
& \vdots \\
\text { ITSO }_{N 1} & =\int_{0}^{\infty} t\left\{Y_{N}\right\}^{2} \cdot d t
\end{aligned}
\end{aligned}
$$

and if $W_{2}(s)=1 / s$ and $W_{1}, W_{3}, \ldots, W_{N}$ are zeroes, then

$$
\begin{aligned}
& \text { ITSO }_{12}=\int_{0}^{\infty} t\left\{Y_{1}\right\}^{2} \cdot d t \\
& \text { ITSO }_{22}=\int_{0}^{\infty} t\left\{Y_{2}\right\}^{2} \cdot d t
\end{aligned}
$$

$$
\mathrm{ITSO}_{N 2}=\int_{0}^{\infty} t\left\{Y_{N}\right\}^{2} \cdot d t
$$

Consecutively, if $W_{N}(s)=1 / s$ and $W_{1}, W_{2}, \ldots, W_{N-1}$ are zeroes, then

$$
\begin{gathered}
\operatorname{ITSO}_{1 N}=\int_{0}^{\infty} t\left\{Y_{1}\right\}^{2} \cdot d t, \\
\operatorname{ITSO}_{2 N}=\int_{0}^{\infty} t\left\{Y_{2}\right\}^{2} \cdot d t, \\
\vdots \\
\operatorname{ITSO}_{N N}=\int_{0}^{\infty} t\left\{Y_{N}\right\}^{2} \cdot d t .
\end{gathered}
$$

Thus the fitness function for specific input $W_{j}$ can be described as follows:

$$
\text { Fitness }_{j}=\sum_{i=1}^{N} \operatorname{ITSO}_{i j}, \quad j=1,2,3, \ldots, N, i \neq q,
$$

where $i$ is the specific output subscript, $j$ is the specific input subscript, and $q$ is the subscript of the output that has been paired with input $j$.

\section{Controlling of Two-Coupled Distillation Column Process}

In this section, the proposed BELBIC and the conventional PID controller are handled regarding the control structure.

3.1. Brain Emotional Learning Based Intelligent Controller (BELBIC) Model. As formerly stated, the considered MIMO system is to be split into several decoupled SISO systems with the minimum possible interrelationship between them. Thus, each of these systems can be independently controlled. In this research, the BELBIC adaptive control structure is utilized for each single control loop. This control structure is based on the functional model of brain emotional learning introduced by $[28,29]$. Over the past decade, this control scheme has proven its robustness in many complex control applications [31-40]. Apart from the application in control systems, the computational model of brain emotional learning in its discrete and continuous form is discussed here, respectively. Afterwards, the methodology of the proposed BSO-BELBIC scheme, which assigns one BELBIC for each decoupled loop, is presented.

The emotional learning computational model designed by $[28,29]$ is graphically illustrated in Figure 3. In mammalian brains, the emotional learning process occurs in a part of the brain called the limbic system, which consists of four main components corresponding to the amygdala, orbitofrontal cortex, thalamus, and the sensory cortex. As shown 


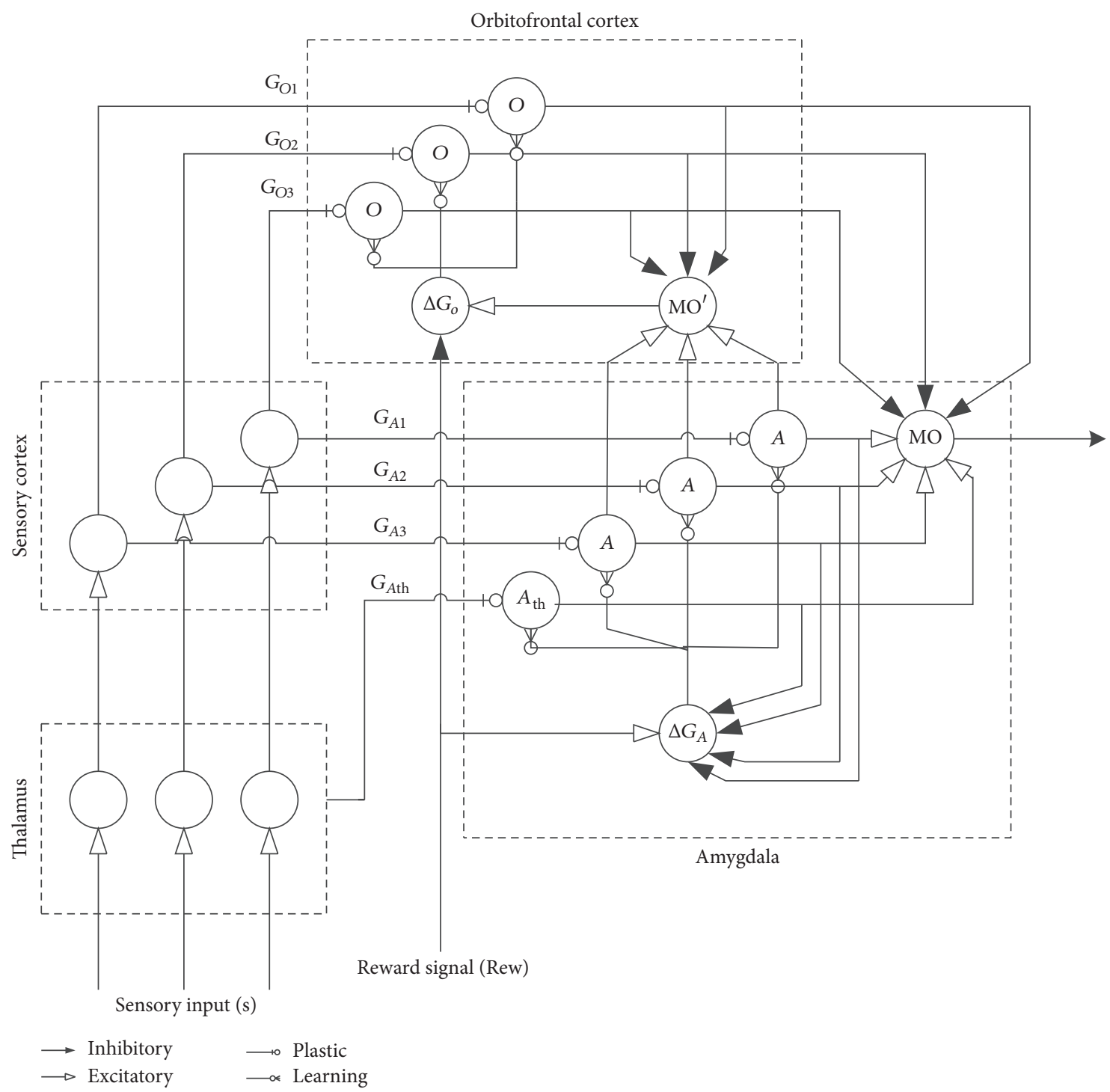

FIGURE 3: Graphical depiction of the brain emotional learning (BEL) process [28, 29].

in the figure, sensory input signals are primarily passed to the thalamus model, which relay the sensory information from the peripheral sensory systems to the sensory cortices. Moreover, the sensory input maximum value is passed directly to the amygdala for the fast response to be insured. Then, the available sensory data are to be processed by sensory cortex model. Hence, highly analyzed data are to be sent to the amygdala and orbitofrontal cortex models. The emotional evaluation of stimuli and the formulation of long-term memories are carried out by the amygdala. Finally, the orbitofrontal cortex is supposed to inhibit inappropriate responses from the amygdala.

The outputs of the model two major components amygdala and orbitofrontal cortex are described in (9) and (10), respectively. The feedback element $\mathrm{MO}^{\prime}$ is defined in (11) as the subtraction of the orbitofrontal cortex inhibitory outputs $\left(O_{i}\right)$ from the summation of amygdala nodes $\left(A_{i}\right)$ excluding $A_{\text {th }}$ node. As illustrated in relation (12), the output (MO) of the brain emotional learning model (BEL) constitutes the subtraction of the orbitofrontal cortex inhibitory outputs $\left(O_{i}\right)$ from the summation of amygdala nodes $\left(A_{i}\right)$ including the $A_{\text {th }}$ node.

$$
\begin{aligned}
A_{i} & =S_{i} G_{A i}, \\
O_{i} & =S_{i} G_{\mathrm{O} i}, \\
\mathrm{MO}^{\prime} & =\sum_{i} A_{i}-\sum_{i} O_{i} \quad\left(\text { excluding } A_{\mathrm{th}} \text { node. }\right), \\
\mathrm{MO} & \left.=\sum_{i} A_{i}-\sum_{i} \mathrm{O}_{i} \quad \text { (including } A_{\mathrm{th}} \text { node. }\right),
\end{aligned}
$$

where $S_{i}$ forms the $i$ th sensory input, and $G_{A}$ and $G_{O}$ are the plastic connection weights of the amygdala and orbitofrontal cortex, respectively. These plastic connection weights are responsible for the emotional change towards specific object 


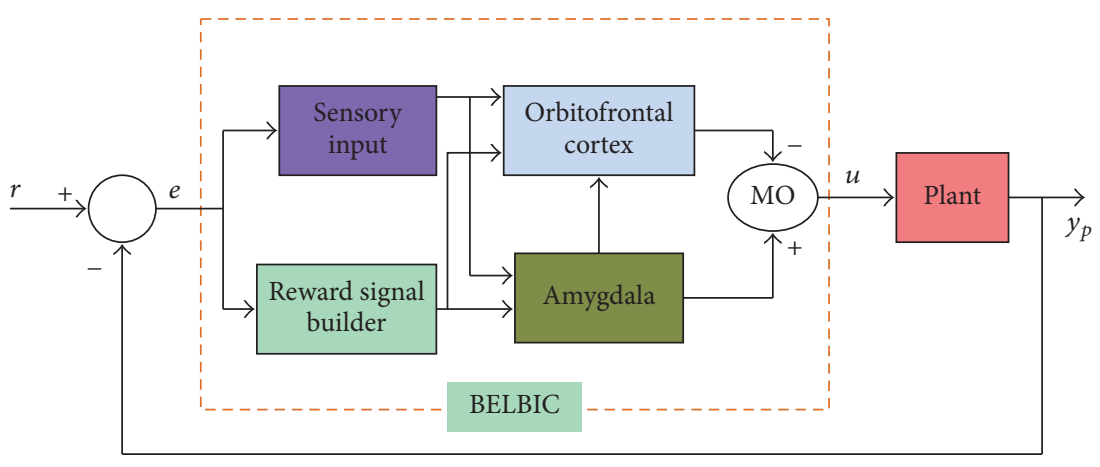

FIGURE 4: Control system configuration using BELBIC.

characteristics. Thus, they constitute the adaptive component in the model structure, as their values are to be updated continuously. While the formulas (13) and (14) represent the discrete form for the change in plastic connection weights, (15) and (16) constitute the continuous one. It is to mention that the continuous form is utilized in this research.

$$
\begin{aligned}
\Delta G_{A i} & =\alpha\left(S_{i} \max \left[0, \operatorname{Rew}-\sum_{j} A_{j}\right]\right), \\
\Delta G_{O i} & =\beta\left(S_{i}\left[\mathrm{MO}^{\prime}-\mathrm{Rew}\right]\right), \\
\frac{d G_{A i}}{d t} & =\alpha \cdot S_{i} \cdot\left(\operatorname{Rew}-A_{i}\right), \\
\frac{d G_{\mathrm{O} i}}{d t} & =\beta \cdot S_{i} \cdot\left(A_{i}-O_{i}-\mathrm{Rew}\right),
\end{aligned}
$$

where $\alpha$ and $\beta$ are learning rate constants, and the symbol Rew forms the reward signal. The operator "max" in the formula (13) is the responsible for maintaining the monotonic learning change of amygdala. This characteristic models the incapability of the amygdala to unlearn the formerly learned emotions [28, 29]. In the continuous form, the operator "max" is eliminated for analytical simplicity [61].

The BELBIC internal structure as well as its interface with the controlled physical plant is illustrated in Figure 4. As shown, sensory input block as well as the reward signal builder manipulates orbitofrontal cortex and amygdala based on the control error signal according to (17) and (18), respectively.

$$
\begin{aligned}
S & =K \cdot e, \\
\operatorname{Rew} & =K_{p} \cdot e+K_{i} \cdot \int e \cdot d t+K_{d} \cdot \frac{d e}{d t},
\end{aligned}
$$

where $K, K_{p}, K_{i}$, and $K_{d}$ besides the learning rate constants ( $\alpha$ and $\beta$ ) constitute the controller parameters, which characterize the controlled dynamic system behavior.

The BELBIC parameterization is one of the current challenges confronting such a novel control structure. In this regard, the utilization of optimization techniques like Particle Swarm Optimization (PSO) has shown a robust behavior [37]. In the frame of this research, the feasibility of applying the Bacterial Swarm Optimization (BSO) algorithm regarding the tuning process of BELBIC parameters is to be investigated. As mentioned in the previous section, the integral time-weighted squared errors (ITSEs) of all control loops are selected to be minimized rather than the integral-squarederrors (ISEs) for its faster settling response. Accordingly, the fitness function is represented in (19).

$$
\begin{aligned}
\text { Fitness function }= & \int_{0}^{\infty} t\left(T_{30} \text { desired }-T_{30}\right)^{2} \cdot d t \\
& +\int_{0}^{\infty} t\left(T_{11} \text { desired }-T_{11}\right)^{2} \cdot d t \\
& +\int_{0}^{\infty} t\left(T_{34} \text { desired }-T_{34}\right)^{2} \cdot d t \\
& +\int_{0}^{\infty} t\left(T_{48} \text { desired }-T_{48}\right)^{2} \cdot d t
\end{aligned}
$$

Twenty-four parameters (six for each loop) should be tuned simultaneously with the aim of minimizing the fitness function.

3.2. PID Control. The main terms that constitute the conventional PID controller are the proportional, the integral, and the derivative terms. The three terms are added to each other as shown in Figure 5. The transfer function of the conventional PID controller is stated in (20).

$$
G_{c}(s)=K_{p}+\frac{K_{i}}{s}+s K_{d}
$$

where $K_{p}, K_{i}$, and $K_{d}$ are proportional gain, integral gain, and a derivative gain, respectively.

The Bacterial Swarm Optimization (BSO) algorithm is utilized regarding the parameterization of PID controllers with the same policies as BELBICs.

\section{Bacterial Swarm Optimization Algorithm}

Bacterial Swarm Optimization Algorithm (BSO) forms a hybrid between two efficient optimization techniques. These algorithms are the Particle Swarm Optimization (PSO) and the Bacterial Foraging Optimization Algorithm (BFOA). 


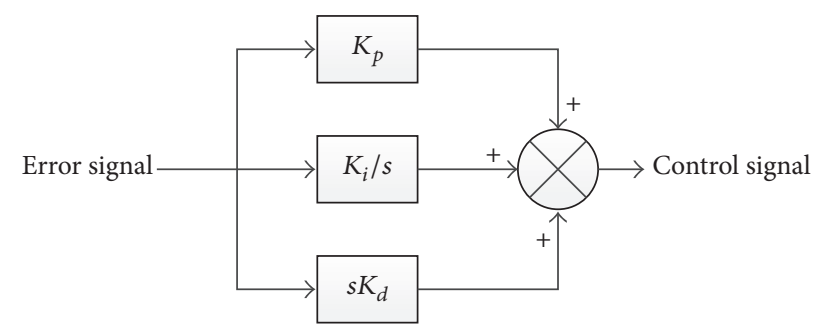

FIGURE 5: Block diagram of the conventional PID controller.

PSO is a stochastic optimization approach inspired from the behavior of the flock of birds, insects, and fish. Every single particle in the search space adjusts its own direction based on its own experience as well as the experience of the most successful particle in the swarm $[43,44]$. Nevertheless, the optimization technique based on the PSO algorithm may lead to entrapment in local optimum solution rather than catch the global one due to the rapidity and simplicity of the algorithm [62].

On the other hand, BFOA is a new bio-inspired algorithm depending on foraging behavior of Escherichia coli (E. coli) bacteria [45]. Bacteria have the tendency to group around the nutrient-rich regions by the activity named chemotaxis. The bacteria which fail to reach nutrient-rich areas may die due to the nutrient lack. However, the ones that survived reproduce the next generation in nutrient-rich areas. Once the current living environment becomes inconvenient to the bacteria, it tends to disperse randomly to search for an alternative environment. Consequently, the optimization technique that simulates the foraging behavior of these bacteria requires a long time for achieving the global optimum solution due to the dependence on random search directions [57].

The time consumed by BFOA finding the global optimum solution can be reduced by granting the $E$. coli bacteria the ability of exchanging social information. This ability is inherited from the PSO technique forming the BSO algorithm. Therefore, BSO algorithm requires less time for the optimum solution determination, while maintaining the BFOA ability in finding a new solution with elimination and dispersal. Thus, the BSO algorithm solves the insufficient scattering problem that confronted the PSO algorithm. Furthermore, the chemotaxis step of BSO technique safeguards against the PSO shortcoming regarding the weak search ability.

As mentioned, the BSO technique is utilized for the parameterization of the decoupling compensation network as well as the BELBIC. As an overview, the procedure of applying the proposed technique on the case study is demonstrated in the process chart in Figure 6. Afterwards, the basic flowchart of the BSO algorithm is presented in Figure 7. Moreover, the pseudocode of the BSO algorithm is stated delivering more details.

The pseudocode of the BSO algorithm is as follows.

Step 1. The initialization of all stated parameters: $p, S, S_{r}, N_{c}$, $N_{s}, N_{\text {re }}, N_{\text {ed }}, P_{\text {ed }}, C(i)(i=1,2, \ldots, S)$, Delta, $w, C_{1}, C_{2}, R_{1}$, and $R_{2}$, where

(i) $p$ is dimension of search space,

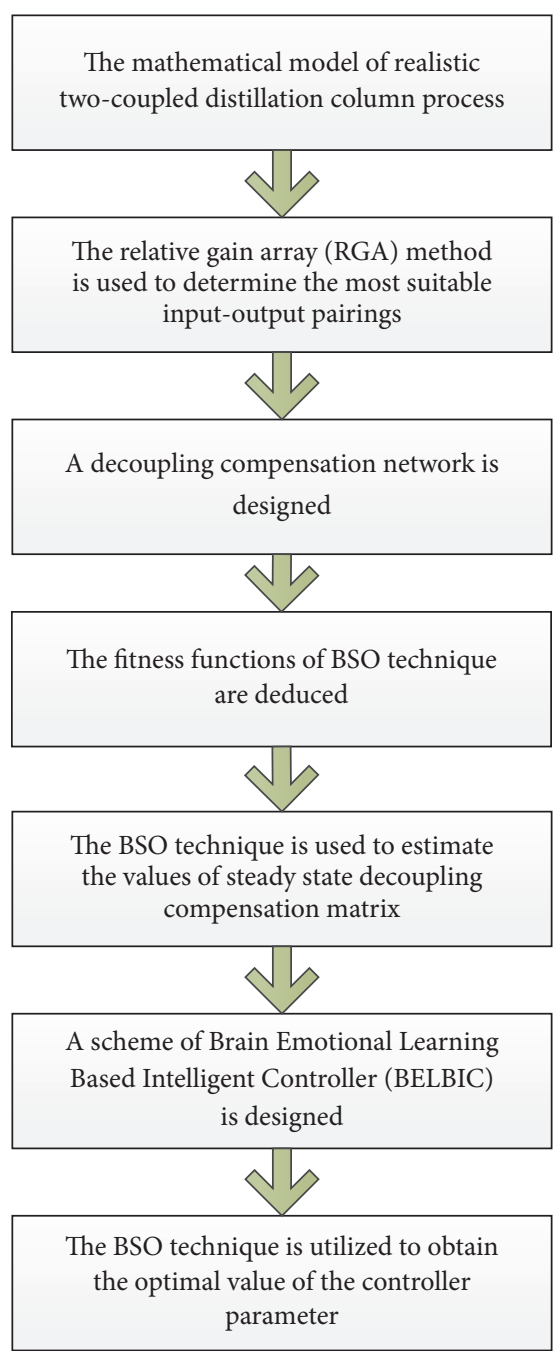

FIGURE 6: Process chart for the main steps of applying the proposed technique on the case study.

(ii) $S$ is the number of bacteria,

(iii) $S_{r}$ is the number of bacteria splits per generation,

(iv) $N_{c}$ is the number of chemotactic steps,

(v) $N_{s}$ is the limits of the length of a swim,

(vi) $N_{\text {re }}$ is the reproduction steps number,

(vii) $N_{\text {ed }}$ is the amount of elimination-dispersal events,

(viii) $P_{\text {ed }}$ is the elimination-dispersal probability,

(ix) $C(i)$ is the bacteria step size length,

(x) Delta is the direction of each bacteria,

(xi) $w$ is the weight of inertia,

(xii) $C_{1}$ is the weight of local information,

(xiii) $C_{2}$ is the weight of global information,

(xiv) $R_{1}, R_{2}$ are two Random numbers.

Step 2. Loop of elimination and dispersal: $l=l+1$. 


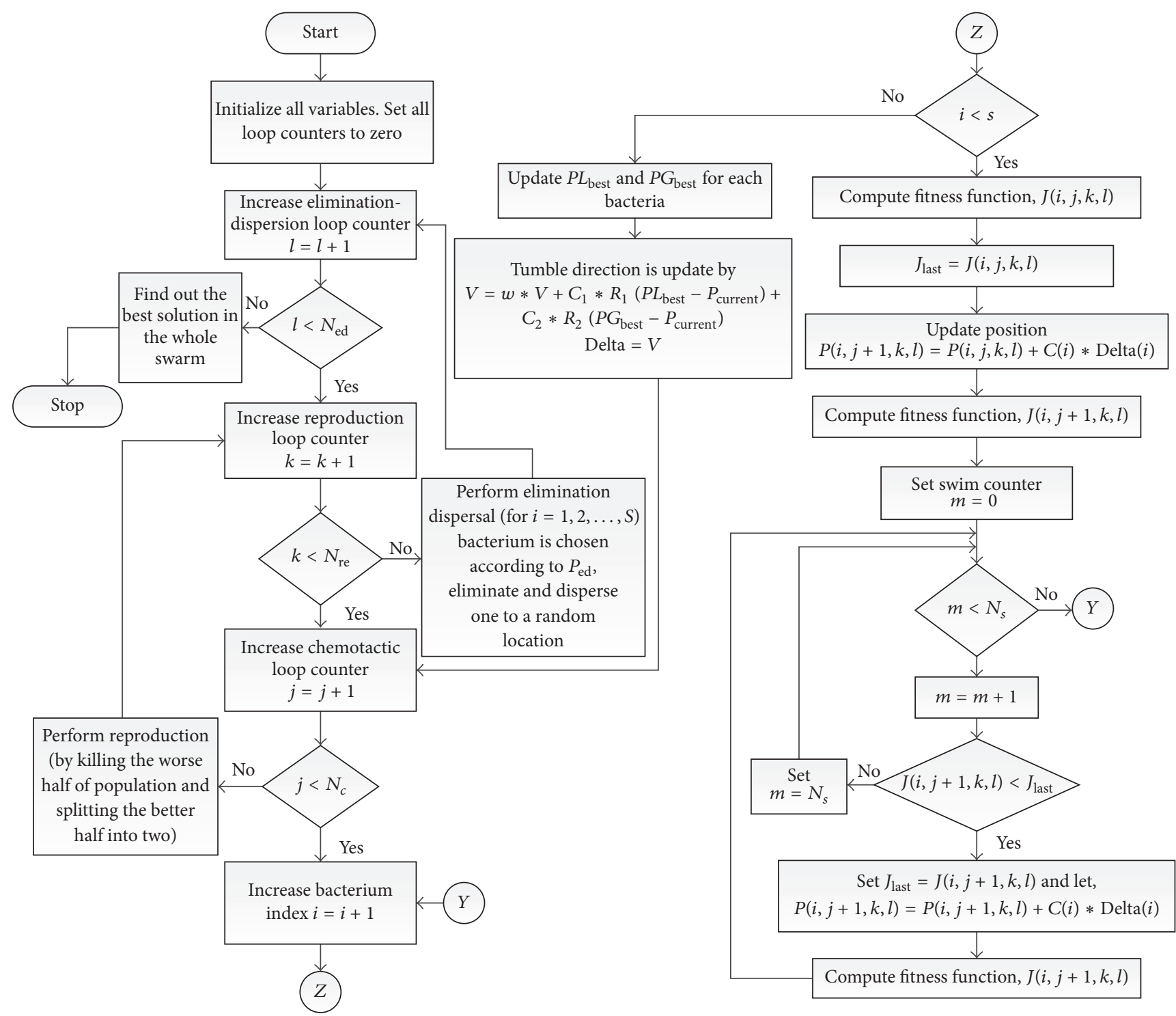

FIGURE 7: Flowchart of BSO algorithm.

Step 3. Loop of reproduction: $k=k+1$.

Step 4. Loop of chemotaxis: $j=j+1$.

Substep 4.1. For $i=1,2, \ldots, S$ each bacterium $i$ moves a chemotactic step as follows.

(a) Calculate cost function, $J(i, j, k, l)$.

(b) Let $J_{\text {last }}=J(i, j, k, l)$ to save the current value of the cost function in order to be able to compare it with the one determined in the next swim.

(c) Let $J_{\text {local }}(i, j)=J_{\text {last }}$; the better cost per each bacteria is going to be chosen to be the local best $J_{\text {local }}$.

(d) Update position $P(i, j+1, k, l)=P(i, j, k, l)+C(i) *$ $\operatorname{Delta}(i)$.

(e) Calculate cost function, $J(i, j+1, k, l)$.

(f) Swim (i) Let $m=0$ (counter for swim length).

(ii) While $m<N_{s}$ (if have not climbed down too long).

(1) Let $m=m+1$

(2) If $J(i, j+1, k, l)<J_{\text {last }}$ (if doing better), let $J_{\text {last }}=J(i, j+1, k, l)$ and let

$$
P(i, j+1, k, l)=P(i, j+1, k, l)+C(i) * \operatorname{Delta}(i)
$$

and use this $P(i, j+1, k, l)$ to calculate the new $J(i, j+1, k, l)$.

(3) For each bacteria estimate the current position and local cost

$$
\begin{aligned}
P_{\text {current }}(i, j+1) & =P(i, j+1, k, l), \\
J_{\text {local }}(i, j+1) & =J(i, j+1, k, l) .
\end{aligned}
$$


(4) Else, let

$$
\begin{gathered}
P_{\text {current }}(i, j+1)=P(i, j+1, k, l), \\
J_{\text {local }}(i, j+1)=J(i, j+1, k, l), \\
m=N_{s} .
\end{gathered}
$$

(5) While statement end.

(g) Go to next bacterium $(i+1)$ if $i \neq S$ (i.e., go to (b) to execute the next bacterium).

Substep 4.2. For each bacteria estimate the local best position $\left(P L_{\text {best }}\right)$ and global best position $\left(P G_{\text {best }}\right)$.

Substep 4.3. For each bacteria estimate the new direction as

$$
\begin{aligned}
V= & w * V+C_{1} * R_{1}\left(P L_{\text {best }}-P_{\text {current }}\right)+C_{2} \\
& * R_{2}\left(P G_{\text {best }}-P_{\text {current }}\right),
\end{aligned}
$$

Delta $=V$.

Step 5 (if $j<N_{c}$, go to Step 4). In this situation keep on chemotaxis since the life of the bacteria is not terminated.

Step 6 (reproduction).

Substep 6.1. For $k$ and $l$ and for each $i=1,2, \ldots, S$, the health of the bacterium $i$ is given by

$$
J_{\text {health }}^{i}=\sum_{j=1}^{N_{c}+1} J(i, j, k, l) .
$$

Sort bacteria cost $J_{\text {health }}$ in ascending order (greater cost indicates lower health).

Substep 6.2. The $S_{r}$ bacteria with the lowest $J_{\text {health }}$ values split and the rest of the $S_{r}$ bacteria die.

Step 7 (if $k<N_{\text {re }}$, return to Step 3). In this instance, the specified maximum number of reproduction steps is not over; therefore the bacteria begin a new generation of a chemotactic loop.

Step 8 (elimination dispersal). For $i=1,2, \ldots, S$ with probability $P_{\text {ed }}$, eliminate and then disperse one to a random place. If $l<N_{\text {ed }}$, then go to Step 2, otherwise end.

\section{Simulation and Results}

The decoupled physical system and its controllers are designed and simulated with MATLAB ${ }^{\mathrm{TM}}$ Simulnik $^{\circledR}$.

The RGA method is applied on the mathematical model of the two-coupled distillation column process, and the resulted matrix is given by

$$
\mathrm{RGA}_{4 \times 4}=\left[\begin{array}{cccc}
-0.0429 & 0.5629 & 0.4083 & 0.0717 \\
1.4559 & 0.5558 & -0.9138 & -0.0980 \\
-0.4647 & -3.1110 & 4.4832 & 0.0926 \\
0.0517 & 2.9923 & -2.9777 & 0.9337
\end{array}\right] .
$$

According to the RGA matrix the suitable input-output pairing is

$$
\begin{aligned}
& \left(T_{11}-\mathrm{SAB}\right), \\
& \left(T_{30}-\mathrm{QE}\right), \\
& \left(T_{34}-\mathrm{RL} 1\right), \\
& \left(T_{48}-\mathrm{RL} 2\right) .
\end{aligned}
$$

Depending on the suitable pairing, the fitness functions of the 1st, 2nd, 3rd, and 4th input are described in (28), (29), (30), and (31), respectively.

$$
\begin{aligned}
& \text { Fitness }_{1}=\mathrm{ITSO}_{11}+\mathrm{ITSO}_{31}+\mathrm{ITSO}_{41} \\
& =\left(16185764.6415 * \lambda_{11}^{2}\right) \\
& +\left(-31208202.2860 * \lambda_{11} * \lambda_{21}\right) \\
& +\left(-29085704.6263 * \lambda_{11} * \lambda_{31}\right) \\
& +\left(-2104353.3818 * \lambda_{11} * \lambda_{41}\right) \\
& +\left(23626420.1763 * \lambda_{21}^{2}\right) \\
& +\left(40518661.8661 * \lambda_{21} * \lambda_{31}\right) \\
& +\left(1053225.6938 * \lambda_{21} * \lambda_{41}\right) \\
& +\left(17625377.5018 * \lambda_{31}^{2}\right) \\
& +\left(1142698.7804 * \lambda_{31} * \lambda_{41}\right) \\
& +\left(112317.1448 * \lambda_{41}^{2}\right) \\
& \text { Fitness }_{2}=\mathrm{ITSO}_{22}+\mathrm{ITSO}_{32}+\mathrm{ITSO}_{42} \\
& =\left(39587638.7663 * \lambda_{12}^{2}\right) \\
& +\left(-25965747.1866 * \lambda_{12} * \lambda_{22}\right) \\
& +\left(-27602372.6861 * \lambda_{12} * \lambda_{32}\right) \\
& +\left(-3313543.6120 * \lambda_{12} * \lambda_{42}\right) \\
& +\left(6085664.7540 * \lambda_{22}^{2}\right) \\
& +\left(12367844.1767 * \lambda_{22} * \lambda_{32}\right) \\
& +\left(1689163.6136 * \lambda_{22} * \lambda_{42}\right) \\
& +\left(6408628.3541 * \lambda_{32}^{2}\right) \\
& +\left(1716766.7412 * \lambda_{32} * \lambda_{42}\right) \\
& +\left(119596.6264 * \lambda_{42}^{2}\right) \\
& \text { Fitness }_{3}=\text { ITSO }_{13}+\text { ITSO }_{23}+\text { ITSO }_{43} \\
& =\left(32387849.9550 * \lambda_{13}^{2}\right) \\
& +\left(-30918315.4051 * \lambda_{13} * \lambda_{23}\right) \\
& +\left(-28156040.3138 * \lambda_{13} * \lambda_{33}\right) \\
& +\left(-1472985.7141 * \lambda_{13} * \lambda_{43}\right) \\
& +\left(21869260.2750 * \lambda_{23}^{2}\right) \\
& +\left(36396234.4688 * \lambda_{23} * \lambda_{33}\right)
\end{aligned}
$$




$$
\begin{aligned}
& +\left(403039.5905 * \lambda_{23} * \lambda_{43}\right) \\
& +\left(15212859.0003 * \lambda_{33}^{2}\right) \\
& +\left(390512.5127 * \lambda_{33} * \lambda_{43}\right) \\
& +\left(57318.4117 * \lambda_{43}^{2}\right)
\end{aligned}
$$

$$
\begin{aligned}
\text { Fitness }_{4}= & \mathrm{ITSO}_{14}+\mathrm{ITSO}_{24}+\mathrm{ITSO}_{34} \\
= & \left(40741561.5731 * \lambda_{14}^{2}\right) \\
& +\left(-37368063.2195 * \lambda_{14} * \lambda_{24}\right) \\
& +\left(-36883365.2610 * \lambda_{14} * \lambda_{34}\right) \\
& +\left(-2495963.4210 * \lambda_{14} * \lambda_{44}\right) \\
& +\left(22451663.5575 * \lambda_{24}^{2}\right) \\
& +\left(39102720.2746 * \lambda_{24} * \lambda_{34}\right) \\
& +\left(623243.6320 * \lambda_{24} * \lambda_{44}\right) \\
& +\left(17326594.9351 * \lambda_{34}^{2}\right) \\
& +\left(837511.9391 * \lambda_{34} * \lambda_{44}\right) \\
& +\left(77118.8721 * \lambda_{44}^{2}\right) .
\end{aligned}
$$

The BSO algorithm parameters' values which are utilized to implement an optimized decoupling network as well as an optimized BELBIC are summarized in Table 1 . The resulting values of the steady state decoupling compensation elements that minimize the above fitness functions are summarized in Table 2.

The resulting best gains' values for different BELBICs that minimize the summation of the integral time-weighted squared errors (ITSEs) for different decoupled loops are presented in Table 3. The best gains' values of the designed conventional PID controllers are shown in Table 4. The PID controllers' parameters are determined utilizing the same algorithm utilized for the design of BELBICs. In this regard, proposed BSO algorithm with the same gains given in Table 1 is used to minimize the same fitness function.

The dynamic behavior of the system is analyzed based on its step response based on the sequential step input shown in Figure 8. In Figure 9, the decoupled system response on the given step sequence is illustrated. As shown, the experimental results demonstrate the efficiency of the designed decoupling technique. Thus, the interrelationship between system inputs and their unpaired outputs is noticeably minimized compared to the formerly deployed techniques [11]. Accordingly, the spikes in the response of the decoupled system outputs on the unpaired inputs are significantly reduced. The step response of the designed closed loop control system is shown in Figure 10.

For verification purposes, the response of the designed control scheme, which is based on the minimization of ITSEs of all control loops utilizing the BSO algorithm, is compared to that of the latest research that considers the same application. It is to mention that the control scheme of the previous research is mainly based on the minimization of the ISE using the PSO algorithm [37]. In Figure 11, the
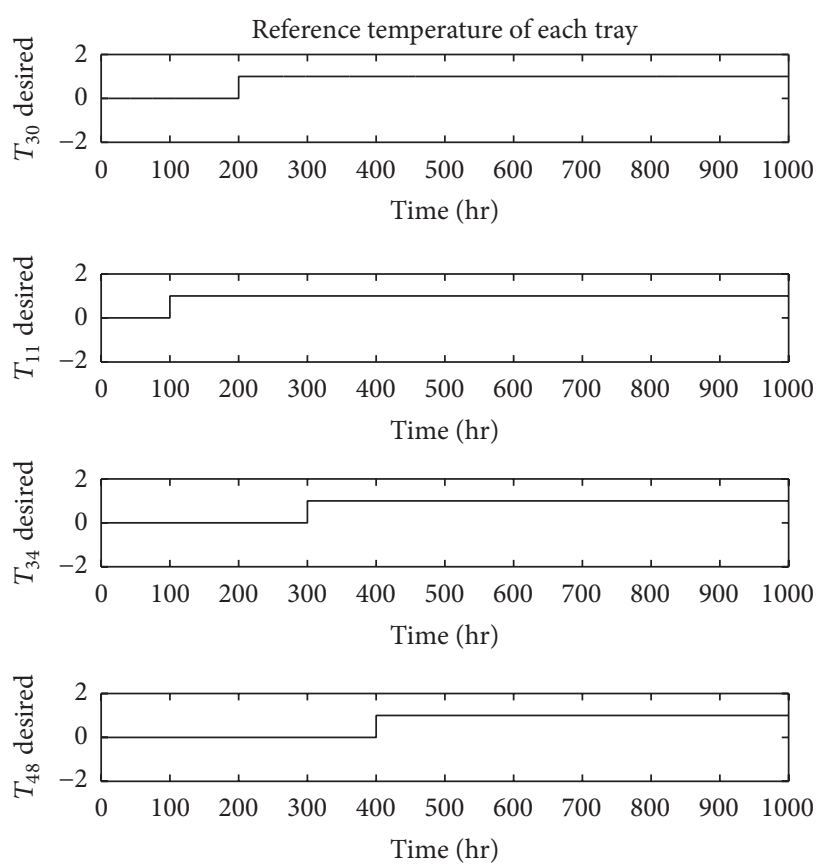

Figure 8: Step changes in system inputs [37].

proposed technique is compared to the former study in terms of step response. Moreover, the steady state errors for both controllers are stated in Table 5.

As shown, the control scheme presented in this research offers a valuable improvement in the last three control loops $\left(T_{11}, T_{34}\right.$, and $\left.T_{48}\right)$ in terms of minimizing steady state errors.

The step response of the proposed BELBICs and conventional PID controllers is compared in the presence of a disturbance step with the final value of " 1 " at the 500th second in the first and the third decoupled loop. The simulation results are presented in Figure 12. In the figure it is clearly recognizable that the robustness of the proposed BELBICs is higher than that of the conventional PID controllers regarding the handling of the unexpected disturbance. The controlled system using BELBICs is better damped as well. On the other side, the PID controllers in all control loops achieve remarkably less steady state error.

For comparison purpose, the PID controllers are designed by utilizing the PSO technique for minimizing the summation of the integral time-weighted squared errors (ITSEs) of system control loops. This controller is to be compared with the one designed using the BSO algorithm regarding the integral time-weighted squared errors (ITSEs) for each control loop, which are listed in Table 6. The remarkable difference between both algorithms regarding ITSEs indicates that the BSO technique is more efficient in determining the global best solution in the field of MIMO control system.

\section{Conclusions}

The challenge of decoupling and controlling higher order multi-input multioutput (MIMO) process is tackled in this 
TABLE 1: Gains of BSO.

\begin{tabular}{|c|c|c|c|}
\hline Parameter & Symbol & BSO for decoupling network implementation & BSO for BELBIC implementation \\
\hline Number of bacteria in the population & $S$ & 50 & 50 \\
\hline Dimension of search space & $p$ & 4 & 24 \\
\hline Maximum number of swim length & $N_{s}$ & 4 & 4 \\
\hline Maximum number of chemotactic steps & $N_{c}$ & 100 & 20 \\
\hline Number of reproductive steps & $N_{\text {re }}$ & 4 & 2 \\
\hline Number of elimination dispersal events & $N_{\text {ed }}$ & 2 & 2 \\
\hline Elimination dispersal probability & $P_{\text {ed }}$ & 0.25 & 0.25 \\
\hline Step size & $C(i)$ & 0.05 & 0.05 \\
\hline Cognitive factor & $C_{1}$ & 1.2 & 1.2 \\
\hline Social acceleration factors & $\mathrm{C}_{2}$ & 0.5 & 0.5 \\
\hline Momentum/inertia & $w$ & 0.9 & 0.9 \\
\hline
\end{tabular}

TABLE 2: Resulting values of steady state decoupling compensation elements based on BSO.

\begin{tabular}{lccccc}
\hline Fitness function & Final value of fitness function & \multicolumn{4}{c}{ Values of steady state decoupling elements $(\lambda \mathrm{s})$} \\
\hline Fitness $_{1}$ & 9.8506 & $\lambda_{11}=0.2453$ & $\lambda_{21}=-0.4755$ & $\lambda_{31}=0.7210$ & $\lambda_{41}=0.8564$ \\
Fitness $_{2}$ & 0.5941 & $\lambda_{12}=-0.0195$ & $\lambda_{22}=-0.1090$ & $\lambda_{32}=-0.0967$ & $\lambda_{42}=1.1934$ \\
Fitness $_{3}$ & 7.6138 & $\lambda_{13}=-0.0481$ & $\lambda_{23}=0.6249$ & $\lambda_{33}=-0.7904$ & $\lambda_{43}=-0.1218$ \\
Fitness $_{4}$ & 0.3040 & $\lambda_{14}=-0.0026$ & $\lambda_{24}=0.1492$ & $\lambda_{34}=-0.1790$ & $\lambda_{44}=0.3273$ \\
\hline
\end{tabular}

TABLE 3: The proper gains of the BELBICs optimized by the BSO for different loops.

\begin{tabular}{|c|c|c|c|c|c|c|}
\hline \multirow{2}{*}{ Loop } & \multicolumn{6}{|c|}{ Gains } \\
\hline & $\alpha$ & $\beta$ & $K$ & $K_{p}$ & $K_{i}$ & $K_{d}$ \\
\hline$\left(\mathrm{QE}, T_{30}\right)$ & 0.2321 & 0.8914 & -0.4830 & 3.4765 & 0.0028 & -0.6471 \\
\hline$\left(\mathrm{SAB}, T_{11}\right)$ & 0.3418 & -1.3651 & 0.3936 & -21.5658 & -1.0949 & -0.7771 \\
\hline$\left(\mathrm{RL} 1, T_{34}\right)$ & 87.3587 & -8.9268 & -0.1020 & 29.4672 & 17.3183 & 14.6593 \\
\hline$\left(\mathrm{RL} 2, T_{48}\right)$ & 17.4282 & 22.6201 & 0.2650 & -62.2460 & -0.6042 & 10.8162 \\
\hline
\end{tabular}

TABLE 4: The proper gains of the PID controllers optimized by the BSO for different loops.

\begin{tabular}{lccc}
\hline Loop & \multicolumn{3}{c}{ Gains } \\
& $K_{p}$ & $K_{i}$ & $K_{d}$ \\
\hline$\left(\mathrm{QE}, T_{30}\right)$ & 1.9662 & 0.3524 & 0.7445 \\
$\left(\mathrm{SAB}, T_{11}\right)$ & 1.0643 & 1.9718 & 0.2621 \\
$\left(\mathrm{RL} 1, T_{34}\right)$ & 1.6276 & 1.4202 & -0.0366 \\
$\left(\mathrm{RL} 2, T_{48}\right)$ & 0.0784 & -3.0889 & 0.8859 \\
\hline
\end{tabular}

TABLE 5: The steady state errors for all loops after control.

\begin{tabular}{lcc}
\hline \multirow{2}{*}{ Loop } & \multicolumn{2}{c}{ Steady state errors } \\
& Former technique & Proposed technique \\
\hline$\left(\mathrm{QE}, T_{30}\right)$ & 0.087510 & 0.1189 \\
$\left(\mathrm{SAB}, T_{11}\right)$ & 0.019915 & 0.0117 \\
$\left(\mathrm{RL} 1, T_{34}\right)$ & 0.036152 & 0.0041 \\
$\left(\mathrm{RL} 2, T_{48}\right)$ & 0.189710 & 0.0207 \\
\hline
\end{tabular}

research. The Bacterial Swarm Optimization (BSO) technique is used to develop an optimized scheme for decoupling
TABle 6: Comparison between PID controllers designed by PSO and $\mathrm{BSO}$ algorithms regarding integral time-weighted squared error ITSE.

\begin{tabular}{lcc}
\hline Loop & \multicolumn{2}{c}{ ITSE } \\
\hline$\left(\mathrm{QE}, T_{30}\right)$ & PSO technique & BSO technique \\
$\left(\mathrm{SAB}, T_{11}\right)$ & 11.5703 & 3.2552 \\
$\left(\mathrm{RL} 1, T_{34}\right)$ & 0.4473 & 1.8333 \\
$\left(\mathrm{RL} 2, T_{48}\right)$ & 2.7937 & 1.8592 \\
Summation & 11.8501 & 5.9165 \\
\hline
\end{tabular}

highly interactive 4 input/4 output two-coupled distillation column processes. The scheme consists of two stages. In the first stage, the optimum group of fitness functions is determined through the analysis of precalculated proper pairing, which is based on the derived relative gain array (RGA). The derivation of the RGA is based on the transfer function matrix of the physical process. In the second stage, the values of decoupling compensation elements $(\lambda s)$ that minimize the interactions are estimated based on the formerly 

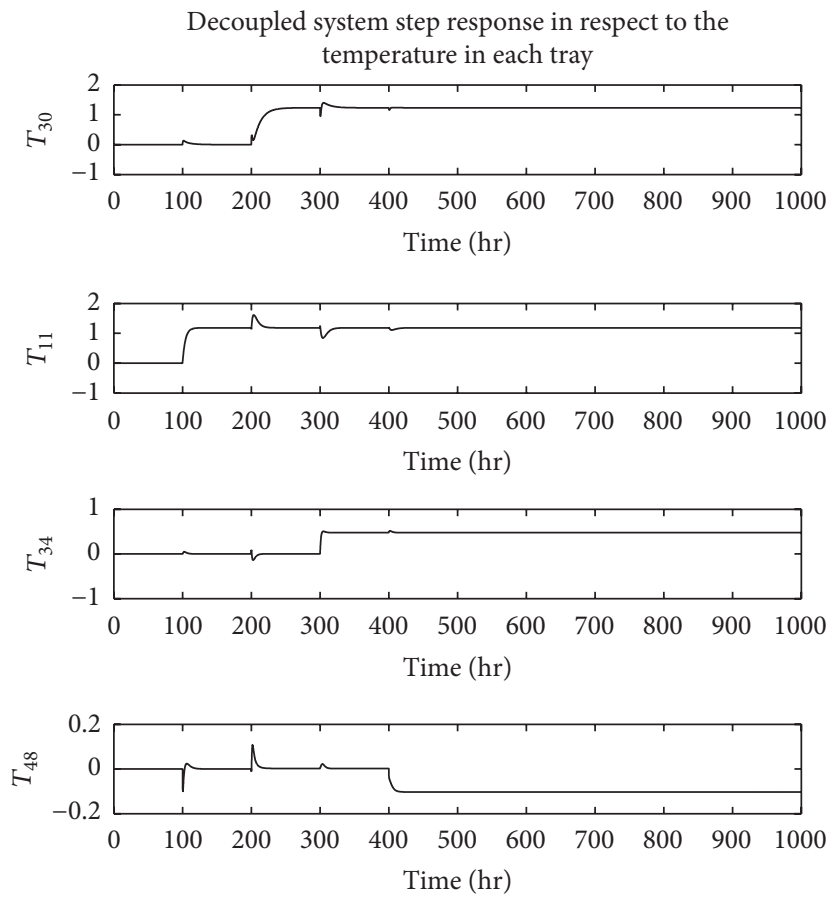

Figure 9: The outputs of different decoupled loops in case of no controllers.
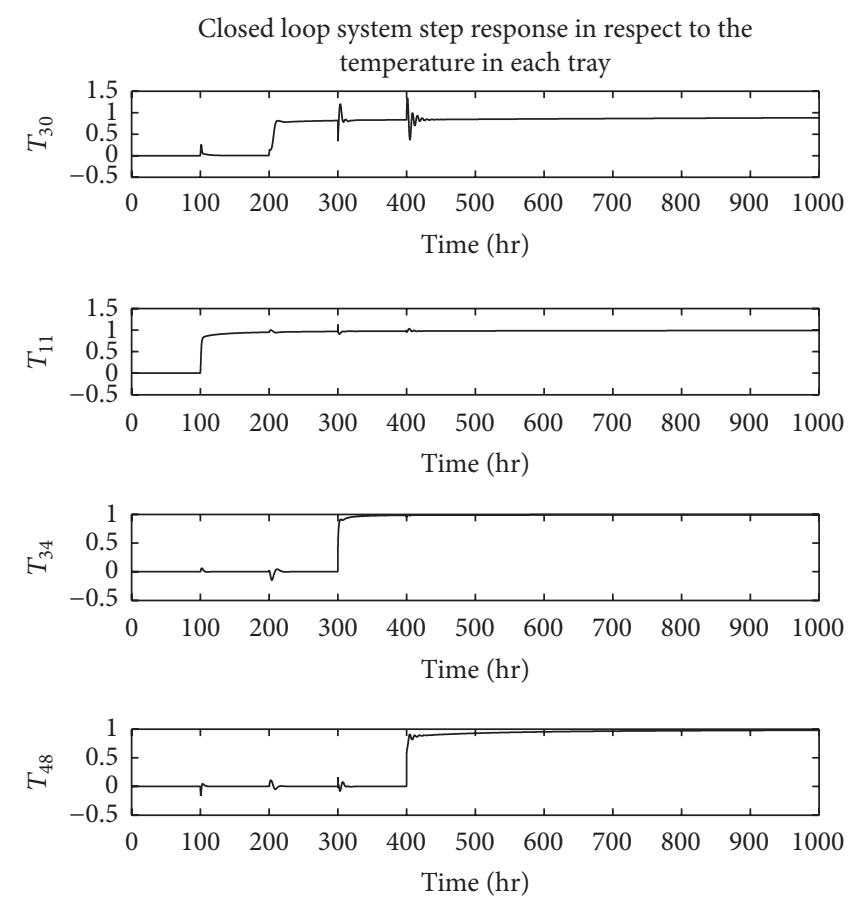

FIGURE 10: The outputs of different decoupled loops in the presence of the controller.

driven fitness functions. Designing the decoupled system based on the general form of the decoupling compensation matrix showed a remarkable improvement in the system dynamics compared to the utilization of the simple form of the compensation matrix. The simulation results showed the efficiency of the proposed BSO technique in estimating steady state decoupling compensation elements values. For control purpose a scheme of Brain Emotional Learning Based Intelligent Controller (BELBIC) is designed and optimized using BSO algorithm to obtain the optimal values of controllers' parameters. Furthermore, PID controllers are developed using the same optimization technique, in order 


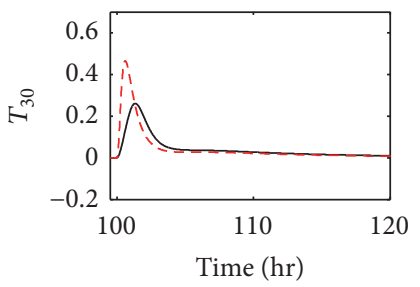

Closed loop system step response in respect to the temperature in each tray
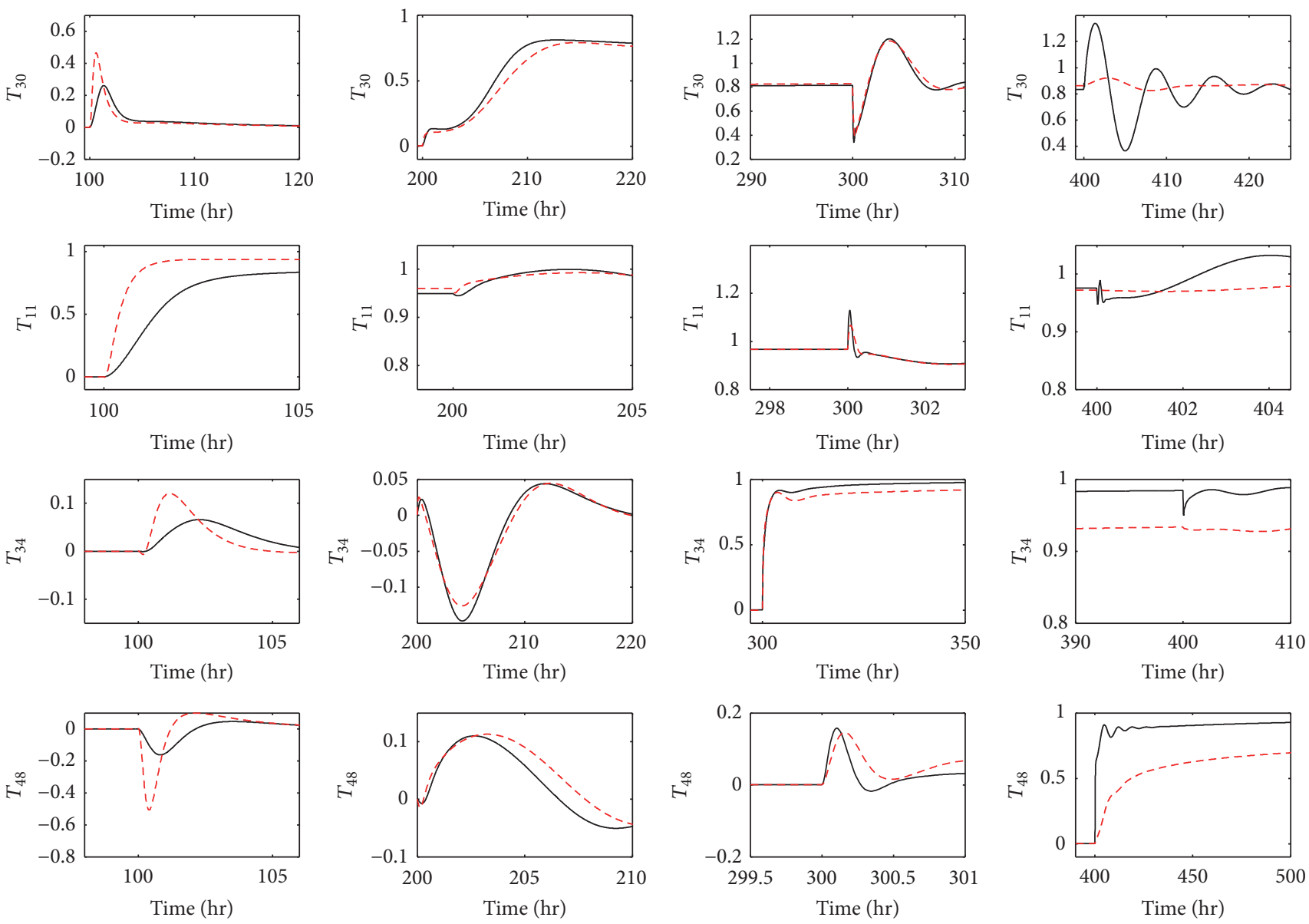

The proposed techniqu
-- The formerly studied
technique

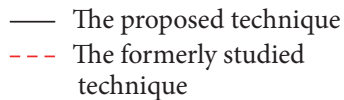
- The proposed technique
- - - The formerly studied technique
— The proposed technique
- - - The formerly studied technique

FIGURE 11: Comparison between the step response of the proposed technique and that of the formerly studied technique.

to validate the robustness of the BELBIC. The robust control behavior of the designed BELBIC-based control scheme is validated in the simulation results. The BELBIC designed using the BSO algorithm showed a remarkable improvement in the transient and steady state errors of the last three control loops compared with the controller designed utilizing the PSO technique.

\section{List of Symbols}

QE: Heat input to the reboiler

SAB: Vapor flow rate in the vapor transfer line

RL1: Reflux ratio in the main column

RL2: Reflux ratio in the second column

$T_{11}$ : Temperature at the 11th tray

$T_{30}$ : Temperature at the 30th tray

$T_{34}$ : Temperature at the 34 th tray

$T_{48}$ : Temperature at the 48th tray

$G(s)$ : Transfer function matrix of the process in $s$ domain $\gamma_{i j}: \quad$ Relative gain between the output " $i$ " and input “ $j$ "

$\Lambda_{\text {ss }}:$ Steady state decoupling compensation matrix

$\lambda_{i j}$ : Decoupling compensation element between the output " $i$ " and input " $j$ "

$Y(s)$ : Output vector of the process

$W(s)$ : Input vector of the decoupling network

MO: The model output of Brain Emotional Learning Based Intelligent Controller (BELBIC)

$\mathrm{O}_{i}$ : Orbitofrontal cortex node

$A_{i}: \quad$ Amygdala node

$S_{i}$ : The ith sensory input

$G_{A}$ : Plastic connection weights of the amygdala

$G_{O}$ : Plastic connection weights of the orbitofrontal cortex

$\alpha$ : The amygdala learning rate

$\beta$ : $\quad$ The orbitofrontal cortex learning rate

Rew: The reward signal

$e$ : Error signal 
Closed loop system step response in respect to the temperature in each tray
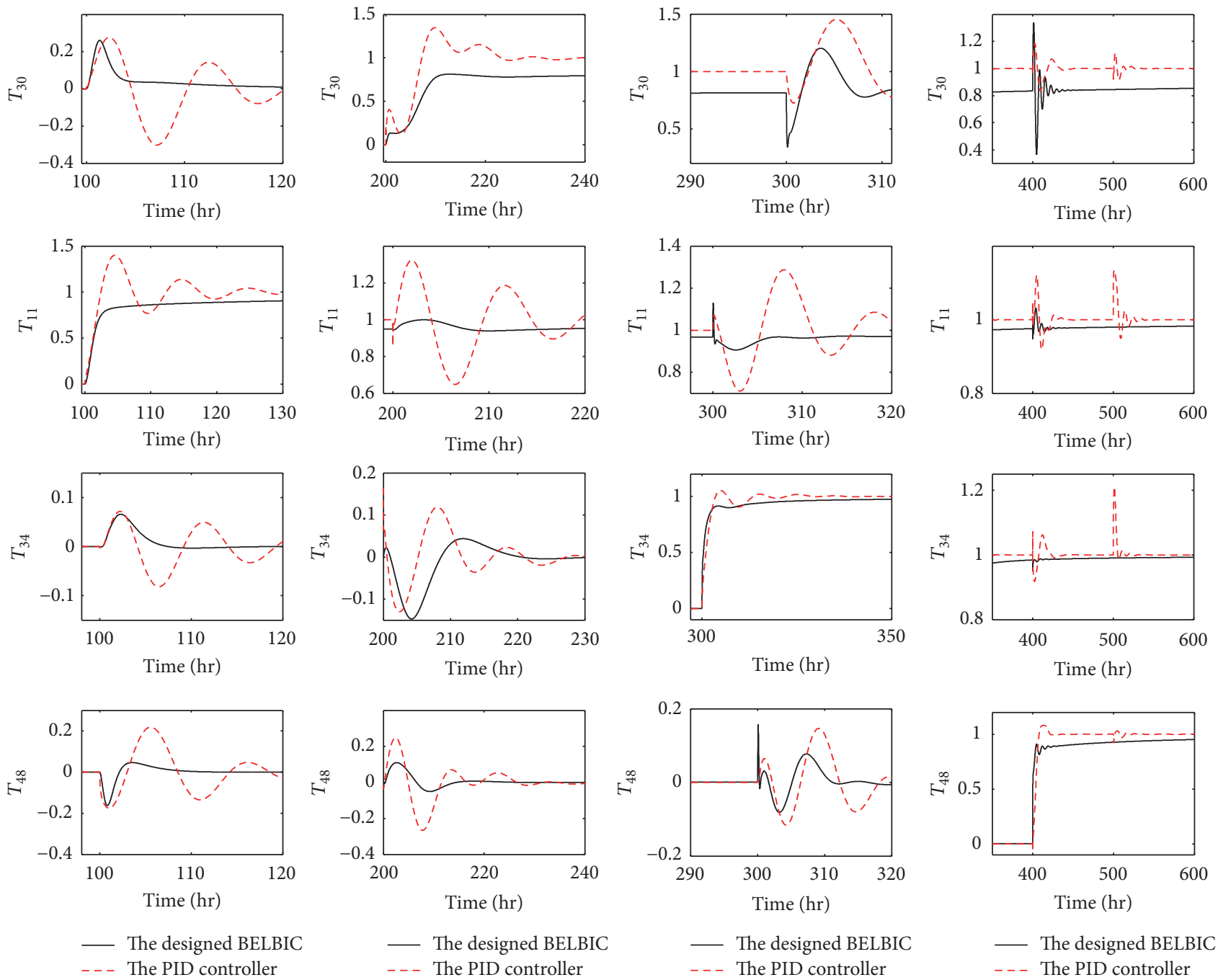

FIGURE 12: Comparison between the step response of the designed BELBIC and that of the PID controller in the presence of disturbance at $t=500$ seconds.

$\begin{array}{ll}K, K_{p}, K_{i}, K_{d}: & \text { Controller parameters } \\ T_{30} \text { desired: } & \text { Reference signal for output } T_{30} \\ T_{11} \text { desired: } & \text { Reference signal for output } T_{11} \\ T_{34} \text { desired: } & \text { Reference signal for output } T_{34} \\ T_{48} \text { desired: } & \text { Reference signal for output } T_{48} \\ p: & \text { Dimension of search space } \\ S: & \text { The number of bacteria } \\ S_{r}: & \text { The number of bacteria splits per generation } \\ N_{c}: & \text { The number of chemotactic steps } \\ N_{s}: & \text { Limits of the length of a swim } \\ N_{\text {re }}: & \text { The reproduction steps number } \\ N_{\text {ed }}: & \text { The amount of elimination-dispersal events } \\ P_{\text {ed }}: & \text { Elimination-dispersal probability } \\ C(i): & \text { The bacteria step size length } \\ \text { Delta: } & \text { The direction of each bacteria } \\ C_{1}: & \text { Weight of local information } \\ C_{2}: & \text { Weight of global information } \\ R_{1}, R_{2}: & \text { Two random numbers. }\end{array}$

\section{Competing Interests}

The authors declare that they have no competing interests.

\section{References}

[1] I.-L. Chien, H.-P. Huang, and J.-C. Yang, "A simple multiloop tuning method for PID controllers with no proportional kick," Industrial and Engineering Chemistry Research, vol. 38, no. 4, pp. 1456-1468, 1999.

[2] F. Vázquez, F. Morilla, and S. Dormido, "An iterative method for tuning decentralized PID controllers," in Proceedings of the 14th IFAC World Congress, Beijing, China, 1999.

[3] M. Lee, K. Lee, C. Kim, and J. Lee, "Analytical design of multiloop PID controllers for desired closed-loop responses," AIChE Journal, vol. 50, no. 7, pp. 1631-1635, 2004. 
[4] Q. Xiong and W.-J. Cai, "Effective transfer function method for decentralized control system design of multi-input multioutput processes," Journal of Process Control, vol. 16, no. 8, pp. 773-784, 2006.

[5] T. N. L. Vu and M. Lee, "Independent design of multi-loop PI/PID controllers for interacting multivariable processes," Journal of Process Control, vol. 20, no. 8, pp. 922-933, 2010.

[6] J. Lieslehto, "MIMO controller design using SISO controller design methods," in Proceedings of the 13th IFAC World Congress, San Francisco, Calif, USA, 1996.

[7] Q.-G. Wang, Y. Zhang, and M.-S. Chiu, "Non-interacting control design for multivariable industrial processes," Journal of Process Control, vol. 13, no. 3, pp. 253-265, 2003.

[8] W. Zhang, L. Chen, and L. Ou, "Algebraic solution to $\mathrm{H}_{2}$ control problems. II. The multivariable decoupling case," Industrial \& Engineering Chemistry Research, vol. 45, no. 21, pp. 7163-7176, 2006.

[9] T. Liu, W. Zhang, and F. Gao, "Analytical decoupling control strategy using a unity feedback control structure for MIMO processes with time delays," Journal of Process Control, vol. 17, no. 2, pp. 173-186, 2007.

[10] M. Waller, J. B. Waller, and K. V. Waller, "Decoupling revisited," Industrial \& Engineering Chemistry Research, vol. 42, no. 20, pp. 4575-4577, 2003.

[11] A. M. El-Garhy and M. E. El-Shimy, "Development of decoupling scheme for high order MIMO process based on PSO technique," Applied Intelligence, vol. 26, no. 3, pp. 217-229, 2007.

[12] W.-J. Cai, W. Ni, M.-J. He, and C.-Y. Ni, "Normalized decoupling-a new approach for MIMO process control system design," Industrial and Engineering Chemistry Research, vol. 47, no. 19, pp. 7347-7356, 2008.

[13] B. T. Jevtović and M. R. Matauek, "PID controller design of TITO system based on ideal decoupler," Journal of Process Control, vol. 20, no. 7, pp. 869-876, 2010.

[14] J. Garrido, F. Vázquez, and F. Morilla, "An extended approach of inverted decoupling," Journal of Process Control, vol. 21, no. 1, pp. 55-68, 2011.

[15] C. Rajapandiyan and M. Chidambaram, "Controller design for MIMO processes based on simple decoupled equivalent transfer functions and simplified decoupler," Industrial and Engineering Chemistry Research, vol. 51, no. 38, pp. 12398-12410, 2012.

[16] E. Bristol, "On a new measure of interaction for multivariable process control," IEEE Transactions on Automatic Control, vol. 11, no. 1, pp. 133-134, 1966.

[17] F. G. Shinskey, Process-Control Systems, McGraw-Hill, New York, NY, USA, 2nd edition, 1979.

[18] T. J. McAvoy, Interaction Analysis, Instrument Society ofAmerica, Research Triangle Park, Durham, NC, USA, 1983.

[19] M. T. Tham, Multivariable Control: An Introduction to Decoupling Control, Department of Chemical and Process Engineering, University of Newcastle Tyne, Newcastle upon Tyne, UK, 1999.

[20] C. S. Zalkind, "Practical approach to Non-interacting control. Parts I and II," Ins. Cont. Systems, vol. 40, 1967.

[21] W. L. Luyben, "Distillation decoupling," AIChE Journal, vol. 16, no. 2, pp. 198-203, 1970.

[22] M. J. Lengare, R. H. Chile, L. M. Waghmare, and B. Parmar, "Auto tuning of PID controller for MIMO processes," International Journal of Electrical, Computer, Electronics and Communication Engineering, vol. 2, pp. 113-116, 2008.
[23] Y. Zhang, S. Li, and Q. Zhu, "Backstepping-enhanced decentralised PID control for MIMO processes with an experimental study," IET Control Theory \& Applications, vol. 1, no. 3, pp. 704712, 2007.

[24] T. S. Chang and A. N. Gündes, "PID controller design with guaranteed stability margin for MIMO systems," in Proceedings of the World Congress on Engineering and Computer Science (WCECS '07), pp. 747-752, 2007.

[25] T. Takagi and M. Sugeno, "Fuzzy identification of systems and its applications to modeling and control," IEEE Transactions on Systems, Man and Cybernetics, vol. 15, no. 1, pp. 116-132, 1985.

[26] K. S. Narendra and K. Parthasarathy, "Identification and control of dynamical systems using neural networks," IEEE Transactions on Neural Networks, vol. 1, no. 1, pp. 4-27, 1990.

[27] R.-J. Wai, J.-D. Lee, and K.-H. Su, "Supervisory enhanced genetic algorithm control for indirect field-oriented induction motor drive," in Proceedings of the IEEE International Joint Conference on Neural Networks, vol. 2, pp. 1239-1244, IEEE, July 2004.

[28] J. Moren and C. A. Balkenius, "Computational model of emotional learning in the Amygdala," in From Animals to Animats 6, pp. 115-124, 2000.

[29] J. Moren, Emotion and learning: a computational model of the Amygdala [Ph.D. thesis], Lund University, Lund, Sweden, 2002.

[30] C. Lucas, D. Shahmirzadi, and N. Sheikholeslami, "Introducing BELBIC: brain emotional learning based intelligent controller," Intelligent Automation and Soft Computing, vol. 10, no. 1, pp. 1122, 2004.

[31] A. R. Mehrabian and C. Lucas, "Emotional learning based intelligent robust adaptive controller for stable uncertain nonlinear systems," International Journal of Computational Intelligence, vol. 2, no. 4, pp. 246-252, 2005.

[32] C. Lucas, R. M. Milasi, and B. N. Araabi, "Intelligent modeling and control of washing machine using locally linear neurofuzzy (LLNF) modeling and modified brain emotional learning based intelligent controller (BELBIC)," Asian Journal of Control, vol. 8, no. 4, pp. 393-400, 2006.

[33] H. Rouhani, M. Jalili, B. N. Araabi, W. Eppler, and C. Lucas, "Brain emotional learning based intelligent controller applied to neurofuzzy model of micro-heat exchanger," Expert Systems with Applications, vol. 32, no. 3, pp. 911-918, 2007.

[34] H. Rouhani, A. Sadeghzadeh, C. Lucas, and B. N. Araabi, "Emotional learning based intelligent speed and position control applied to neurofuzzy model of switched reluctance motor," Control and Cybernetics, vol. 36, no. 1, pp. 75-95, 2007.

[35] H. Guoyong, Z. Ziyang, and W. Daobo, "Brain emotional learning based intelligent controller for nonlinear system," in Proceedings of the 2008 2nd International Symposium on Intelligent Information Technology Application (IITA '08), vol. 2, pp. 660-663, IEEE, Shanghai, China, December 2008.

[36] S. Jafarzadeh, R. Mirheidari, M. R. J. Motlagh, and M. Barkhordari, "Designing PID and BELBIC controllers in path tracking problem," International Journal of Computers, Communications and Control, vol. 3, pp. 343-348, 2008.

[37] H. T. Dorrah, A. M. El-Garhy, and M. E. El-Shimy, "PSOBELBIC scheme for two-coupled distillation column process," Journal of Advanced Research, vol. 2, no. 1, pp. 73-83, 2011.

[38] S. Ale Aghaee, C. Lucas, and K. Amiri Zadeh, "Applying brain emotional learning based intelligent controller (belbic) to multiple-area power systems," Asian Journal of Control, vol. 14, no. 6, pp. 1580-1588, 2012. 
[39] A. Jain, G. Jain, and A. Kuchhal, "Brain emotional learning based intelligent controller and its application to continuous stirred tank reactor," Computer Engineering and Intelligent Systems, vol. 4, no. 5, pp. 1-9, 2013.

[40] M. K. Sharma and A. Kumar, "Performance comparison of Brain Emotional Learning-Based Intelligent Controller (BELBIC) and PI controller for Continually Stirred Tank Heater (CSTH)," in Computational Advancement in Communication Circuits and Systems, pp. 293-301, Springer India, 2015.

[41] A. Colorni, M. Dorigo, and V. Maniezzo, "Distributed optimization by ant colonies," in Proceedings of the 1st European Conference on Artificial Life, vol. 142, pp. 134-142, Paris, France, December 1991.

[42] D. Whitley, "A genetic algorithm tutorial," Statistics and Computing, vol. 4, no. 2, pp. 65-85, 1994.

[43] J. Kennedy and R. Eberhart, "Particle swarm optimization," in Proceedings of the 1995 IEEE International Conference on Neural Networks. Part 1 (of 6), pp. 1942-1948, Piscataway, NJ, USA, December 1995.

[44] Eberhart and Y. Shi, "Particle swarm optimization: developments, applications and resources," in Proceedings of the Congress on Evolutionary Computation, IEEE Service Center, Seoul, Republic of Korea, May 2001.

[45] K. M. Passino, "Biomimicry of bacterial foraging for distributed optimization and control," IEEE Control Systems Magazine, vol. 22, no. 3, pp. 52-67, 2002.

[46] E. S. Ali and S. M. Abd-Elazim, "Bacteria foraging optimization algorithm based load frequency controller for interconnected power system," International Journal of Electrical Power and Energy Systems, vol. 33, no. 3, pp. 633-638, 2011.

[47] K. S. Kumar and T. Jayabarathi, "Power system reconfiguration and loss minimization for an distribution systems using bacterial foraging optimization algorithm," International Journal of Electrical Power and Energy Systems, vol. 36, no. 1, pp. 13-17, 2012.

[48] S. M. Abd-Elazim and E. S. Ali, "Power system stability enhancement via bacteria foraging optimization algorithm," Arabian Journal for Science and Engineering, vol. 38, no. 3, pp. 599-611, 2013.

[49] M. M. de Menezes, P. B. de Araujo, and F. E. de Vargas, "Bacterial foraging optimization algorithm used to adjust the parameters of Power System Stabilizers and Thyristor Controlled Series Capacitor-Power Oscillation Damping controller," in Proceedings of the 11th IEEE/IAS International Conference on Industry Applications (INDUSCON '14), pp. 1-6, IEEE, Juiz de Fora, Brazil, December 2014.

[50] R. Majhi, G. Panda, G. Sahoo, P. K. Dash, and D. P. Das, "Stock market prediction of S\&P 500 and DJIA using bacterial foraging optimization technique," in Proceedings of the IEEE Congress on Evolutionary Computation (CEC '07), pp. 2569-2575, IEEE, Singapore, September 2007.

[51] R. Majhi, G. Panda, B. Majhi, and G. Sahoo, "Efficient prediction of stock market indices using adaptive bacterial foraging optimization (ABFO) and BFO based techniques," Expert Systems with Applications, vol. 36, no. 6, pp. 10097-10104, 2009.

[52] C. Li, Application of Bacterial Foraging Optimization PID Control in VAV System, Shandong Normal University School of Information Science \& Engineering, Jinan, China, 2013.

[53] A. S. Oshaba and E. S. Ali, "Bacteria foraging: a new technique for speed control of DC series motor supplied by photovoltaic system," International Journal of WSEAS Transactions on Power Systems, vol. 9, pp. 185-195, 2014.
[54] W. M. Korani, H. T. Dorrah, and H. M. Emara, "Bacterial foraging oriented by particle swarm optimization strategy for PID tuning," in Proceedings of the IEEE International Symposium on Computational Intelligence in Robotics and Automation (CIRA '09), pp. 445-450, December 2009.

[55] A. Biswas, S. Dasgupta, S. Das, and A. Abraham, "Synergy of PSO and bacterial foraging optimization-a comparative study on numerical benchmarks," in Innovations in Hybrid Intelligent Systems, pp. 255-263, Springer, Berlin, Germany, 2007.

[56] R. Anguluri, A. Abraham, and V. Snasel, "A hybrid bacterial foraging-PSO algorithm based tuning of optimal FOPI speed controller," Acta Montanistica Slovaca, vol. 16, no. 1, pp. 55-65, 2011.

[57] S. M. Abd-Elazim and E. S. Ali, "Synergy of particle swarm optimization and bacterial foraging for TCSC damping controller design," International Journal of WSEAS Transactions on Power Systems, vol. 8, pp. 74-84, 2013.

[58] S. M. Abd-Elazim and E. S. Ali, "A hybrid particle swarm optimization and bacterial foraging for power system stability enhancement," Complexity, vol. 21, no. 2, pp. 245-255, 2015.

[59] L. Lang and E. D. Gilles, "A case-study of multivariable control for a multicomponent distillation unit on a pilot plant scale," in Proceedings of the IEEE American Control Conference, pp. 101106, Pittsburgh, Pa, USA, June 1989.

[60] H. Unbehauen, "Control systems, robotics and automationvol.II-controller design in time-domain," in Encyclopedia of Life Support Systems (EOLSS), Developed under the Auspices of the UNESCO, The Encyclopedia of Life Support Systems (EOLSS), Paris, France, 2009, http://www.eolss.net/.

[61] A. Jain, Computational modeling of the brain limbic system and its application in control engineering [Ph.D. thesis], Thapar University, 2009.

[62] D. P. Rini, S. M. Shamsuddin, and S. S. Yuhaniz, "Particle swarm optimization: technique, system and challenges," International Journal of Computer Applications, vol. 14, no. 1, pp. 19-26, 2011. 

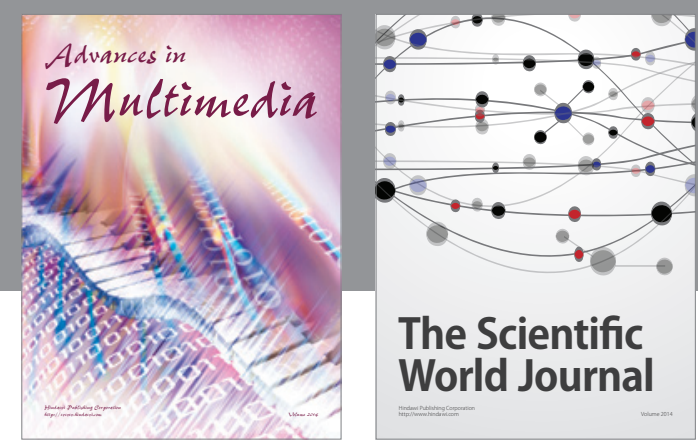

The Scientific World Journal
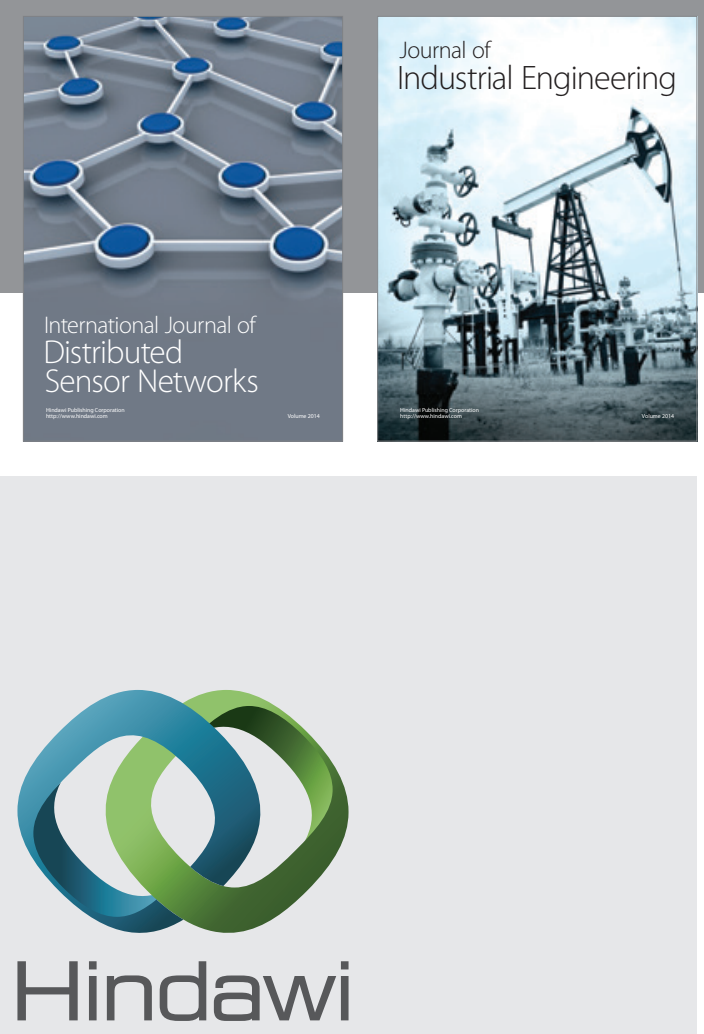

Submit your manuscripts at

http://www.hindawi.com

\section{Computer Networks} and Communications
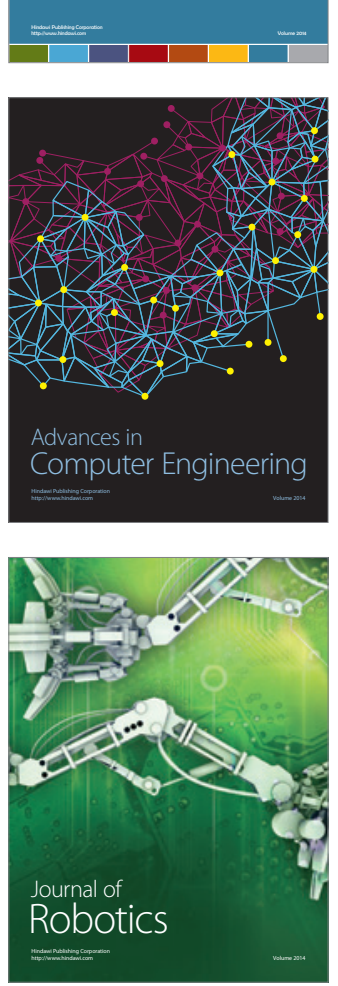
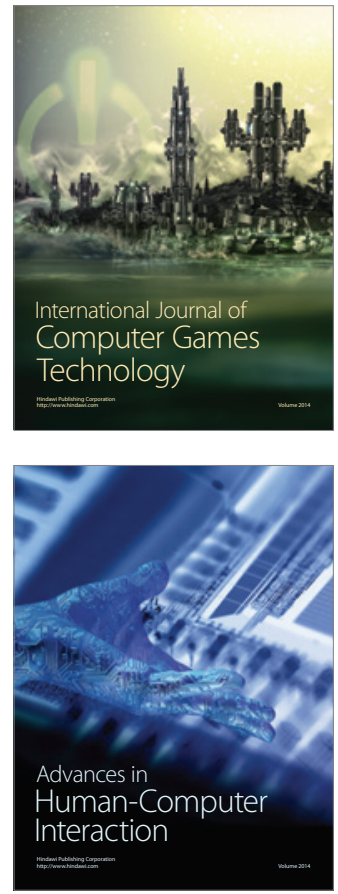
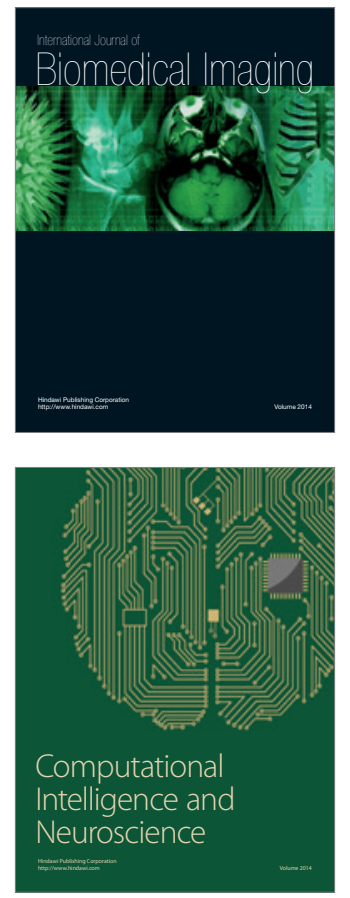
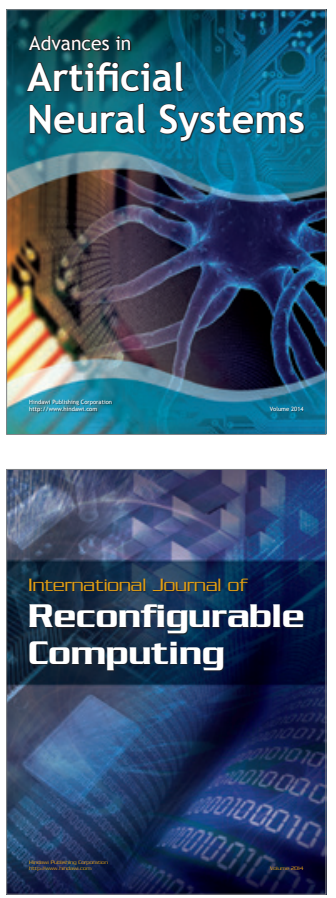
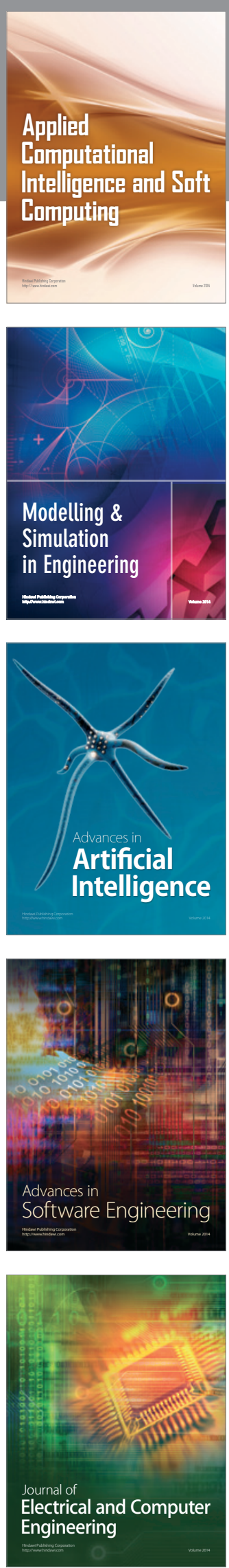